\title{
Atmospheric fate of a series of saturated alcohols: kinetic and mechanistic study
}

\author{
Inmaculada Colmenar ${ }^{1,2}$, Pilar Martin $^{1,2}$, Beatriz Cabañas ${ }^{1,2}$, Sagrario Salgado ${ }^{1,2}$, Araceli Tapia ${ }^{1,2}$, and \\ Inmaculada Aranda ${ }^{1,2}$ \\ ${ }^{1}$ Universidad de Castilla La Mancha, Departamento de Química Física, Facultad de Ciencias y Tecnologías Químicas, \\ Avda. Camilo José Cela S/N, 13071 Ciudad Real, Spain \\ ${ }^{2}$ Universidad de Castilla La Mancha, Instituto de Combustión y Contaminación Atmosférica (ICCA), \\ Camino Moledores S/N, 13071 Ciudad Real, Spain
}

Correspondence: Pilar Martín (mariapilar.martin@uclm.es)

Received: 22 July 2019 - Discussion started: 9 August 2019

Revised: 27 November 2019 - Accepted: 10 December 2019 - Published: 21 January 2020

\begin{abstract}
The atmospheric fate of a series of saturated alcohols (SAs) was evaluated through kinetic and reaction product studies with the main atmospheric oxidants. These SAs are alcohols that could be used as fuel additives. Rate coefficients (in $\mathrm{cm}^{3}$ molecule $\mathrm{e}^{-1} \mathrm{~s}^{-1}$ ) measured at $\sim 298 \mathrm{~K}$ and atmospheric pressure $(720 \pm 20$ Torr $)$ were as follows: $k_{1}((\mathrm{E})-4-$ methylcyclohexanol $+\mathrm{Cl})=(3.70 \pm 0.16)$ $\times 10^{-10}, k_{2}((\mathrm{E})-4-$ methylcyclohexanol $+\mathrm{OH})=(1.87 \pm$ $0.14) \times 10^{-11}, k_{3}\left((\mathrm{E})\right.$-4-methylcyclohexanol $\left.+\mathrm{NO}_{3}\right)=$ $(2.69 \pm 0.37) \times 10^{-15}, k_{4}(3,3$-dimethyl-1-butanol $+\mathrm{Cl})=$ $(2.69 \pm 0.16) \times 10^{-10}, k_{5}(3,3$-dimethyl-1-butanol $+\mathrm{OH})$ $=(5.33 \pm 0.16) \times 10^{-12}, k_{6}(3,3$-dimethyl-2-butanol $+\mathrm{Cl})$ $=(1.21 \pm 0.07) \times 10^{-10}$, and $k_{7}$ (3,3-dimethyl-2-butanol $+\mathrm{OH})=(10.50 \pm 0.25) \times 10^{-12}$. The main products detected in the reaction of SAs with $\mathrm{Cl}$ atoms (in the absence/presence of $\mathrm{NO}_{x}$ ), $\mathrm{OH}$ radicals, and $\mathrm{NO}_{3}$ radicals were (E)-4-methylcyclohexanone for the reactions of (E)-4methylcyclohexanol, 3,3-dimethylbutanal for the reactions of 3,3-dimethyl-1-butanol, and 3,3-dimethyl-2-butanone for the reactions of 3,3-dimethyl-2-butanol. Other products such as formaldehyde, 2,2-dimethylpropanal, and acetone have also been identified in the reactions of $\mathrm{Cl}$ atoms and $\mathrm{OH}$ radicals with 3,3-dimethyl-1-butanol and 3,3-dimethyl-2-butanol. In addition, the molar yields of the reaction products were estimated. The products detected indicate a hydrogen atom abstraction mechanism at different sites on the carbon chain of alcohol in the case of $\mathrm{Cl}$ reactions and a predominant site in the case of $\mathrm{OH}$ and $\mathrm{NO}_{3}$ reactions, confirming the predictions of structure-activity relationship (SAR) methods. Tro-
\end{abstract}

pospheric lifetimes $(\tau)$ of these SAs have been calculated using the experimental rate coefficients. Lifetimes are in the range of $0.6-2 \mathrm{~d}$ for $\mathrm{OH}$ reactions, $7-13 \mathrm{~d}$ for $\mathrm{NO}_{3}$ radical reactions, and 1-3 months for $\mathrm{Cl}$ atoms. In coastal areas, the lifetime due to the reaction with $\mathrm{Cl}$ decreases to hours. The calculated global tropospheric lifetimes, and the polyfunctional compounds detected as reaction products in this work, imply that SAs could contribute to the formation of ozone and nitrated compounds at local, regional, and even global scales. Therefore, the use of saturated alcohols as additives in diesel blends should be considered with caution.

\section{Introduction}

A multitude of scientific studies on combustion emissions confirm that fossil fuels, especially diesel fuel, are the substances mainly responsible for air pollution. The loss of air quality and its consequences for health as well as for global warming are some of the most important problems caused by air pollution (https://www.iea.org, last access: 3 June 2019). These consequences have led governments to set restrictive limits on the presence of certain pollutants in the atmosphere, such as in the case of particulate matter (PM; the Euro 6 emissions standard) and to develop biofuels (Sikarwara et al., 2017) as alternatives to conventional fuels. Biodiesel is obtained from the transesterification of oils of animal or vegetable origin. Moreover, the fermentation of vegetal biomass gives methanol and or ethanol (bioethanol). These lower al- 
cohols have been used as fuels and show advantages, such as a reduction in smoke, due to the presence of the $\mathrm{OH}$ group that increases the oxygen content during the combustion process (Ren et al., 2008; Lapuerta et al., 2010; Sarathy et al., 2014; Sikarwara et al., 2017). However, several studies have shown certain complications in the use of lower alcohols due to their low cetane number, the high latent heat of vaporization, and the high resistance to autoignition (Karabektas and Hosoz, 2009). In order to avoid or to minimize these limitations, alcohol-diesel blends and alcoholdiesel emulsions have been used in diesel engines (Ozsezen et al., 2011). Another alternative is the use of longer-chain alcohols (propanol, $n$-butanol, isobutanol, and $n$-pentanol) that have superior fuel properties compared with lower alcohols when mixed with diesel fuel (Cheung et al., 2014; Kumar and Saravanan, 2016; Li et al., 2017).

Alcohols are present in the atmosphere from a wide variety of anthropogenic and biogenic sources (Calvert et al., 2011). Methanol, ethanol, and isopropanol are some of the main alcohols detected in urban areas such as Osaka and Sao Paulo cities (Nguyen et al., 2001) with concentrations of 5.88.2 and 34.1-176.3 ppbv, respectively. Other alcohols, such as (E)-4-methylcyclohexanol, have been identified in exhaust gas emissions resulting from burning fuel blends containing $7 \% v / v$ (B7) and $20 \% v / v$ (B20) of soy bean/palm biodiesel (84\%/16\%) (Lopes et al., 2014). 3,3-Dimethyl-1-butanol is a glass-forming material used as a chemical intermediate in organic syntheses (https://www.capotchem.com, last access: 3 June 2019). 3,3-Dimethyl-2-butanol is a potential precursor for prohibited chemical weapons such as soman, which is a nerve agent (Murty et al., 2010). It is also used in the conversion of ribose-and glucose-binding proteins into receptors for pinacolyl methylphosphonic acid (Allert et al., 2004). The use of long-chain alcohols as biofuels could present an additional important source of these alcohols in the atmosphere. Therefore, prior to use, it is necessary to study the reactivity of long-chain alcohols under atmospheric conditions in order to establish and evaluate their atmospheric impact.

In the case of small alcohols, the knowledge of their reactivity is well established and indicates that the main degradation process of saturated alcohols in the atmosphere is the reaction with hydroxyl radicals $(\mathrm{OH})$ during the daytime (Grosjean, 1997; Atkinson and Arey, 2003; Atkinson et al., 2006; Calvert et al., 2011; Caravan et al., 2015; Mellouki et al, 2015). Kinetics with chlorine $(\mathrm{Cl})$ atoms are expected to be high; therefore, reactions with $\mathrm{Cl}$ could also be an important degradation route, especially in coastal areas where concentration peaks of $\mathrm{Cl}$ atoms can be found. Reactions with molecular ozone $\left(\mathrm{O}_{3}\right)\left(k \leq 10^{-20} \mathrm{~cm}^{3}\right.$ molecule $\left.{ }^{-1} \mathrm{~s}^{-1}\right)$ and the nitrate radical $\left(\mathrm{NO}_{3}\right)\left(\sim 10^{-15} \mathrm{~cm}^{3}\right.$ molecule $\left.{ }^{-1} \mathrm{~s}^{-1}\right)$ are too low to make a significant contribution to their degradation. However, the determination of the rate coefficients and the reaction products of alcohols with the nitrate radical are also necessary to better understand the general reactivity of alcohols in the atmosphere, as the reactions with this radi- cal are a source of $\mathrm{OH}$ during nighttime (Finlayson-Pitts and Pitts, 2000).

Although some studies into the reactivity of higher alcohols have been carried out over the last few years (Ballesteros et al., 2007; Hurley et al., 2009; Andersen et al., 2010; Calvert et al., 2011; Moreno et al., 2012, 2014; Mellouki et al., 2015), the kinetic and mechanistic database is still scarce. In the case of 3,3-dimethyl-1-butanol and 3,3-dimethyl-2butanol (derivatives of 1-butanol and 2-butanol), there is a lack of information with respect to the diurnal reactivity (Moreno et al., 2014; Mellouki et al., 2015). Regarding cyclic alcohols, only data concerning the reactivity of $\mathrm{Cl}$ atoms and $\mathrm{OH}$ radicals with cyclohexanol (Bradley et al., 2001; Ceacero-Vega et al., 2012) and OH with cyclopentanol (Wallington et al., 1988) have been reported.

Therefore, in the present work, studies into the kinetics and the products of gas-phase reactions of some SAs, such as (E)-4-methylcyclohexanol (4MCHexOH), 3,3dimethyl-1-butanol (3,3DM1ButOH), and 3,3-dimethyl-2butanol (3,3DM2ButOH) with $\mathrm{Cl}$ atoms and with $\mathrm{OH}$ and $\mathrm{NO}_{3}$ radicals have been carried out. These SAs have been chosen for their potential use as biofuels and because their reactivity has not yet been evaluated. Therefore, our work will permit us to complete the kinetic and mechanism database, to improve our knowledge of the atmospheric chemistry of higher alcohols, and to assess their environmental chemical impact in the case of their future use as biofuels.

\section{Experimental section}

\subsection{Kinetic experiments}

The reactions of a series of SAs with the main atmospheric oxidants were studied:
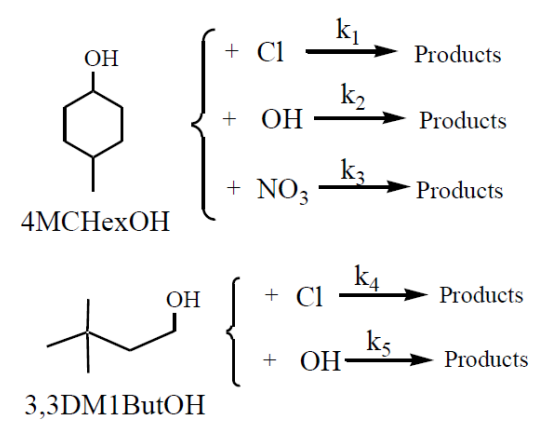

3,3DM1ButOH

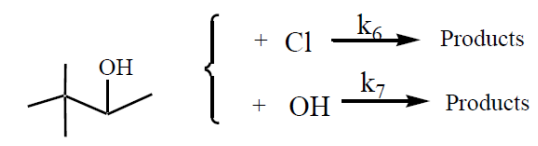

3,3DM2ButOH

Rate coefficients were determined using a relative rate method. This method relies on the assumption that the organic compound (the $\mathrm{SA}$ ) and the reference compound $(R)$, are removed solely by their reactions with the oxidants (Ox: 
$\mathrm{OH}$ and $\mathrm{NO}_{3}$ radicals and $\mathrm{Cl}$ atoms):

$\mathrm{Ox}+\mathrm{SA} \rightarrow$ Products $\left(k_{\mathrm{SA}}\right)$

$\mathrm{Ox}+R \rightarrow$ Products $\left(k_{\mathrm{R}}\right)$

Here, $k_{\mathrm{SA}}$ and $k_{\mathrm{R}}$ are the rate coefficients of the SA and the reference compound, respectively.

On the assumption that the SA and the reference compound are only consumed by reaction with the oxidants, the kinetic treatment for the reactions expressed by Reactions (R8) and (R9) gives the following relationship:

$\ln \left(\frac{[\mathrm{SA}]_{0}}{[\mathrm{SA}]_{t}}\right)=\frac{k_{\mathrm{SA}}}{k_{\mathrm{R}}} \ln \left(\frac{[R]_{0}}{[R]_{t}}\right)$,

where $[\mathrm{SA}]_{0},[R]_{0},[\mathrm{SA}]_{t}$, and $[R]_{t}$ are the initial concentrations and those at time $t$ for the SA and the reference compound, respectively. Two reference compounds were used with each oxidant to ensure that the reference compound had no influence on the overall rate coefficient.

According to Eq. (1), a plot of $\ln \left([\mathrm{SA}]_{0} /[\mathrm{SA}]_{t}\right)$ versus $\ln \left([R]_{0} /[R]_{t}\right)$ should be a straight line that passes through the origin. The slope of this plot gives the ratio of the rate coefficients $k_{\mathrm{SA}} / k_{\mathrm{R}}$. Therefore, the value of $k_{\mathrm{SA}}$ can be obtained if the rate coefficient $k_{\mathrm{R}}$ of the reference compound is known.

The experimental systems have been described in previous works (Tapia et al., 2011; Martin et al., 2013); thus, only a brief description is given here. Kinetic measurements were performed at room temperature $(\sim 298 \mathrm{~K})$ and atmospheric pressure $(720 \pm 20$ Torr) by employing two separate experimental setups. In the first experimental framework, a $50 \mathrm{~L}$ Pyrex ${ }^{\circledR}$ glass reactor was coupled to an Fourier transform infrared spectrometer as a detection technique ("online" analysis). Inside of the Pyrex ${ }^{\circledR}$ glass reactor there was a multireflection system with three mirrors that allowed for an infrared radiation path of $2.8-200 \mathrm{~m}$. This reactor is known as white cell (Saturn Series Multi-Pass cell). The FTIR spectrometer (Thermo Nicolet 6700) was equipped with a $\mathrm{KBr}$ beam splitter and liquid-nitrogen-cooled MCT detector. Typically, for each spectrum, 60 interferograms were co-added over $98 \mathrm{~s}$ and approximately 30-40 spectra were recorded per experiment with a spectral resolution of $1 \mathrm{~cm}^{-1}$. In the second experimental setup, a Teflon ${ }^{\circledR} 500 \mathrm{~L}$ gas bag reactor with solid-phase microextraction (SPME) for sampling and gas chromatography with a time-of-flight mass spectrometer (SPME/GC-TOFMS; AccuTOF GCv, JEOL) was utilized ("off-line" analysis). Samples were collected by exposing a 50/30 mm DVB/CAR/PDMS SPME (divinylbenzene/carboxen/polydimethylsiloxane; SUPELCO) for $5 \mathrm{~min}$ during the reaction and then thermally desorbing it for $15 \mathrm{~min}$ at $250^{\circ} \mathrm{C}$ in the heated GC injection port. A capillary column $(30 \mathrm{~m} \times 0.3 \mathrm{~mm}$ i.d. $\times 1.0 \mathrm{~mm}$ film thickness, TRACSIL TRB1701, Teknokroma) was used to separate the compounds. The chromatographic conditions used for the analysis were as follows: the injector was $250^{\circ} \mathrm{C}$; the interface was $250^{\circ} \mathrm{C}$; the initial oven temperature was $40^{\circ} \mathrm{C}$ for $4 \mathrm{~min}$; the ramp was $30^{\circ} \mathrm{C} \mathrm{min}^{-1}$ to $120^{\circ} \mathrm{C}$ and this temperature was held for $6 \mathrm{~min}$; the second ramp was $30^{\circ} \mathrm{C} \mathrm{min}^{-1}$ to $200^{\circ} \mathrm{C}$ and this temperature was held for $3 \mathrm{~min}$.

In each independent experiment, the reactants were injected into the reactors from a vacuum line by dragging them with a stream of carrier gas that was used in the reaction. Both reactors were inside a metallic housing that had a rack of actinic lamps (Philips, TL $40 \mathrm{~W}$, Actinic BL, $\left.\lambda_{\max }=360 \mathrm{~nm}\right)$ in the walls. A scheme of the experimental systems is shown in Fig. S1 in the Supplement.

The kinetic experiments for the $\mathrm{Cl}$ and $\mathrm{OH}$ reactions were performed in the $50 \mathrm{~L}$ Pyrex ${ }^{\circledR}$ glass reactor coupled to a FTIR spectrometer. A spectral subtraction procedure was used to derive the concentrations of the reactant and reference compounds at time $t=0$ and time $t$. The reaction of $\mathrm{NO}_{3}$ with $4 \mathrm{MCHexOH}$ was studied using a $500 \mathrm{~L}$ Teflon ${ }^{\circledR}$ reactor in order to minimize the wall deposition and dilution effects of consecutive additions of $\mathrm{N}_{2} \mathrm{O}_{5}$. Chlorine atoms and $\mathrm{OH}$ radicals were obtained via the photolysis of $\mathrm{Cl}_{2}$ in $\mathrm{N}_{2}$ and methyl nitrite $\left(\mathrm{CH}_{3} \mathrm{ONO}\right)$ in the presence of $\mathrm{NO}$ in air. Methyl nitrite was synthesized in the laboratory as described elsewhere (Taylor et al., 1980).

Nitrate radicals were generated in situ in the dark by the thermal decomposition of $\mathrm{N}_{2} \mathrm{O}_{5}$ (Atkinson et al., 1984, 1988). $\mathrm{N}_{2} \mathrm{O}_{5}$ was obtained by mixing $\mathrm{O}_{3}$ with an excess of $\mathrm{NO}_{2}$ (Schott and Davidson, 1958). Prior to the kinetic experiments, a series of tests under dark and photolytic conditions were carried out to evaluate secondary reactions, such as wall depositions and the photodegradation of all reactants.

The range of the concentrations of reactants employed were as follows: $2-16 \mathrm{ppm}$ of $4 \mathrm{MCHexOH}, 3-9 \mathrm{ppm}$ of $3,3 \mathrm{DM} 1 \mathrm{ButOH}$ and 3,3DM2ButOH, 9-30 ppm of $\mathrm{Cl}_{2}, 4-$ $13 \mathrm{ppm}$ of 1-butene and 2-methylpropene, 7-14 ppm of propene and cyclohexene, 5-7 ppm of isopropanol, 3-5 ppm of 2-methyl-2-butanol, 26-55 ppm of $\mathrm{CH}_{3} \mathrm{ONO}, 20-60 \mathrm{ppm}$ of NO, 3-4 ppm of 2-ethyl-1-hexanol, and 4-5 ppm of 1butanol. For reactions of $4 \mathrm{MCHexOH}$ with nitrate radicals, two to five additions of $\mathrm{N}_{2} \mathrm{O}_{5}$ with concentrations between 8 and $36 \mathrm{ppm}$ were made per experiment.

\subsection{Product experiments}

The product study was carried out at room temperature $(\sim 298 \mathrm{~K})$ and at a pressure of $720 \pm 20$ Torr of synthetic air, employing the two experimental setups previously described. In some experiments carried out in the $50 \mathrm{~L} \mathrm{Pyrex}^{\circledR}$ reactor, the simultaneous identification of products was performed using both detection techniques. In the abovementioned experiments, one sample of reaction mixture was taken from this reactor using the SPME and subsequently analyzed by GC-TOFMS. In addition, independent experiments using SPME/GC-TOFMS in a $150 \mathrm{~L}$ Teflon ${ }^{\circledR}$ reactor were developed. Product analyses were carried out using the same procedure as for the kinetic experiments, without the reference compound, and employing synthetic air as the bath gas. On 
this occasion, the heating of the oven was changed slightly in order to get a better separation and to detect the products generated. The temperature ramps of the oven employed in the chromatograph were as follows: $40^{\circ} \mathrm{C}$ for $4 \mathrm{~min}$; a ramp of $25^{\circ} \mathrm{C} \mathrm{min}-1$ to $120^{\circ} \mathrm{C}$ that was held for $10 \mathrm{~min}$; and a second ramp of $25^{\circ} \mathrm{C} \mathrm{min}^{-1}$ to $200^{\circ} \mathrm{C}$ that was held for $4 \mathrm{~min}$.

The qualitative analysis in the FTIR experiments was carried out using the FTIR library that provided the FTIR spectrophotometer (Aldrich vapor phase sample library, https://www.thermofisher.com/search/browse/ results?customGroup=Spectral+Libraries, last access: 3 June 2019) and/or the FTIR database of Eurochamp (https://data.eurochamp.org/data-access/spectra/, last access: 3 June 2019).

For the SPME/GC-TOFMS experiments, the NIST WebBook (https://webbook.nist.gov/chemistry/, last access: 3 June 2019) and the mass spectra database of the instrument were used to identify the products. Calibrated FTIR spectra and SPME/GC-TOFMS chromatograms were used for quantification in cases where the product was commercially available.

The molecular yields of the reaction products were estimated from the slopes of plots of the concentration of product formed versus the amounts of SA $(\Delta[\mathrm{SA}])$ consumed. In the cases where an important loss of the reaction product by reaction of the oxidant and/or by photolytic process was observed, the concentration of the product was corrected using the formulism of Tuazon et al. (1986) (see Sect. S1 in the Supplement). The ranges of the concentrations of the reactants employed were as follows: 2-14 ppm of SA, 8-31 ppm of $\mathrm{Cl}_{2}, 12-57$ ppm of NO, 19-66 ppm of $\mathrm{CH}_{3} \mathrm{ONO}$, and 636 ppm of $\mathrm{N}_{2} \mathrm{O}_{5}$.

The chemicals used were as follows: 4MCHexOH (97\%, Aldrich), 3,3DM1ButOH, and 3,3DM2ButOH (98\%, Aldrich); 1-butene, propene, 2-methyl-2-butanol, isopropanol, 2-methylpropene, 4-methylcyclohexanone, and cyclohexene ( $\geq 99 \%$, Aldrich); 2-ethyl-1-hexanol ( $\geq 99 \%$, Fluka), 1-butanol (99.8\%, Aldrich), 3,3-dimethylbutanal (95\%, Aldrich), and 3,3-dimethyl-2-butanone (98\%, Aldrich); and NO (99\%, Praxair), $\mathrm{Cl}_{2}$ (>99.8\%, Praxair), synthetic air (Praxair ultrahigh purity $99.999 \%$ ), and $\mathrm{N}_{2}$ $\left(99.999 \%\right.$, Praxair). For $\mathrm{N}_{2} \mathrm{O}_{5}$ synthesis, $\mathrm{N}_{2} \mathrm{O}_{4}$ was used (>99.5\%, Fluka), and $\mathrm{P}_{2} \mathrm{O}_{5}(98 \%$, such as desiccant, Fluka) and $\mathrm{O}_{3}$ were synthesized using a generator (model TRCE-5000), $5 \mathrm{gO}_{3} \mathrm{~h}^{-1}$ (OZOGAS).

\section{Results and discussion}

\subsection{Kinetic study}

Preliminary test experiments indicated that dark heterogeneous reactions and photolytic losses of SAs and reference compounds could be considered negligible under our experimental conditions $\left(k \approx 10^{-6} \mathrm{~s}^{-1}\right)$. The kinetic study was car- ried out at room temperature $(\sim 298 \mathrm{~K})$ and at $720 \pm 20$ Torr of $\mathrm{N}_{2}$ gas for $\mathrm{Cl}$ atom reactions and synthetic air for $\mathrm{OH}$ radical reactions. Nitrate radical experiments were performed using $\mathrm{N}_{2}$ gas in a $500 \mathrm{~L}$ Teflon reactor and employing the SPME/GC-TOFMS system. A number of injections of the unreacted mixture were carried out in order to determine the associated precision of the sampling method to be used in the error analysis (Brauers and Finlayson-Pitts, 1997). The standard deviations $(\sigma)$ were as follows: $3.7 \%$ for $4 \mathrm{MCHexOH}$, $1.7 \%$ for 1-butanol, and $3.5 \%$ for 2-ethyl-1-hexanol.

Figure 1 shows examples of the kinetic data plotted according to Eq. (1) for the reactions of SAs with different atmospheric oxidants. A good correlation was obtained with an intercept close to zero, which indicated the absence of secondary reactions. From the slopes of the plots $\left(k_{\mathrm{SA}} / k_{\mathrm{R}}\right)$ and using known values of the rate coefficients for the reference compounds employed $\left(k_{\mathrm{R}}\right)$, the value of the absolute rate coefficient for each saturated alcohol $\left(k_{\mathrm{SA}}\right)$ was determined. Rate coefficients of the reactions of reference compounds with $\mathrm{Cl}$ atom reactions (in $10^{-10} \mathrm{~cm}^{3}$ molecule $\mathrm{e}^{-1} \mathrm{~s}^{-1}$ ) were $3.40 \pm 0.28$ for 2 methylpropene, $3.38 \pm 0.48$ for 1-butene (Ezzel et al., 2002), and $2.23 \pm 0.31$ for propene (Ceacero-Vega et al., 2009); rate coefficients of the reactions of reference compounds with $\mathrm{OH}$ radicals (in $10^{-11} \mathrm{~cm}^{3}$ molecule $\mathrm{s}^{-1} \mathrm{~s}^{-1}$ ) were $2.66 \pm 0.40$ for propene (Atkinson and Aschmann, 1989), $6.77 \pm 1.69$ for cyclohexene (Atkinson and Arey, 2003), $0.51 \pm 0.008$ for isopropanol (IUPAC http://www.iupac-kinetic.ch.cam.ac.uk, last access: 19 December 2017), and $0.36 \pm 0.06$ for 2methyl-2-butanol (Jiménez et al., 2005); and rate coefficients of the reactions of reference compounds with $\mathrm{NO}_{3}$ radicals (in $10^{-15} \mathrm{~cm}^{3}$ molecule $\mathrm{s}^{-1}$ ) were $3.14 \pm 0.97$ for 1 butanol and $2.93 \pm 0.92$ 2-ethyl-1-hexanol (Gallego-Iniesta et al., 2010).

The ratios of the rate coefficients, $k_{\mathrm{SA}} / k_{\mathrm{R}}$, the absolute rate coefficients, and the weighted averages are shown in Table 1 . The error of $k_{\mathrm{SA}} / k_{\mathrm{R}}$ was given by 2 times the statistical deviation calculated from the least squares fit of the plot of Eq. (1). The uncertainties for rate coefficients of SA $\left(\sigma_{\mathrm{kSA}}\right)$ were calculated from the uncertainty of the slope of plots $\left(\sigma_{\text {slope }}\right)$ and the uncertainty of the reference $\left(\sigma_{\mathrm{kR}}\right)$ using the propagation of uncertainties. The average value of the rate coefficients obtained with different reference compounds and their associated errors were obtained by the weighted average (see the footnote to Table 1). The rate coefficients obtained in this work are the first kinetic data reported for these SAs; therefore, the results obtained cannot be compared with literature values.

It is well established that the gas-phase reaction mechanism of saturated organic compounds (alkanes, alcohols, ethers, etc.) with atmospheric oxidants $(\mathrm{Cl}$ atoms as well as $\mathrm{OH}$ and $\mathrm{NO}_{3}$ radicals) are initiated via hydrogen atom abstraction from the organic compound to form a stable molecule and an alkyl radical (Finlayson-Pitts and Pitts, 2000; Atkinson and Arey, 2003; Calvert et al., 2011; Zie- 
Table 1. Rate coefficient ratios, absolute rate coefficients, and average rate coefficients for the reactions of a series of $\mathrm{SAs}$ with $\mathrm{Cl}$ atoms and $\mathrm{OH}$ and $\mathrm{NO}_{3}$ radicals at $298 \mathrm{~K}$ and $720 \pm 20$ Torr of pressure. Rate coefficients, $k$, are shown in cubed centimeters per molecule per second $\left(\mathrm{cm}^{3}\right.$ molecule $\left.\mathrm{s}^{-1}\right)$.

\begin{tabular}{|c|c|c|c|c|}
\hline Reaction & Reference & $\left(k_{\mathrm{SA}} / k_{\mathrm{R}}\right) \pm 2 \sigma$ & $\left(k_{\mathrm{SA}} \pm 2 \sigma\right)^{\mathrm{a}} / 10^{-10}$ & $\left(\bar{k}_{\mathrm{SA}} \pm 2 \sigma\right)^{\mathrm{b}} / 10^{-10}$ \\
\hline \multirow[t]{6}{*}{ 3,3DM1ButOH $+\mathrm{Cl}$} & 1-Butene & $0.85 \pm 0.03$ & $2.89 \pm 0.42$ & $2.69 \pm 0.16$ \\
\hline & & $0.79 \pm 0.02$ & $2.68 \pm 0.38$ & \\
\hline & & $0.76 \pm 0.02$ & $2.58 \pm 0.37$ & \\
\hline & Propene & $1.18 \pm 0.02$ & $2.63 \pm 0.37$ & \\
\hline & & $1.21 \pm 0.03$ & $2.70 \pm 0.38$ & \\
\hline & & $1.22 \pm 0.03$ & $2.71 \pm 0.38$ & \\
\hline \multirow[t]{6}{*}{ 3,3DM2ButOH + Cl } & 1-Butene & $0.42 \pm 0.01$ & $1.42 \pm 0.21$ & $1.21 \pm 0.07$ \\
\hline & & $0.35 \pm 0.01$ & $1.17 \pm 0.17$ & \\
\hline & & $0.41 \pm 0.01$ & $1.38 \pm 0.20$ & \\
\hline & Propene & $0.48 \pm 0.01$ & $1.08 \pm 0.15$ & \\
\hline & & $0.50 \pm 0.02$ & $1.12 \pm 0.16$ & \\
\hline & & $0.56 \pm 0.03$ & $1.26 \pm 0.19$ & \\
\hline \multirow[t]{6}{*}{$4 \mathrm{MCHexOH}+\mathrm{Cl}$} & 2-Methylpropene & $1.08 \pm 0.03$ & $3.69 \pm 0.32$ & $3.70 \pm 0.16$ \\
\hline & & $1.16 \pm 0.02$ & $3.95 \pm 0.33$ & \\
\hline & & $0.98 \pm 0.05$ & $3.35 \pm 0.32$ & \\
\hline & 1-Butene & $1.14 \pm 0.03$ & $3.86 \pm 0.56$ & \\
\hline & & $1.12 \pm 0.03$ & $3.78 \pm 0.55$ & \\
\hline & & $1.15 \pm 0.04$ & $3.90 \pm 0.57$ & \\
\hline Reaction & Reference & $\left(k_{\mathrm{SA}} / k_{\mathrm{R}}\right) \pm 2 \sigma$ & $\left(k_{\mathrm{SA}} \pm 2 \sigma\right)^{\mathrm{a}} / 10^{-12}$ & $\left(\bar{k}_{\mathrm{SA}} \pm 2 \sigma\right)^{\mathrm{b}} / 10^{-12}$ \\
\hline \multirow[t]{6}{*}{ 3,3DM1BuOH $+\mathrm{OH}$} & Isopropanol & $1.00 \pm 0.04$ & $5.09 \pm 0.20$ & $5.33 \pm 0.16$ \\
\hline & & $1.13 \pm 0.09$ & $5.78 \pm 0.47$ & \\
\hline & & $1.12 \pm 0.08$ & $5.72 \pm 0.40$ & \\
\hline & 2-Methyl-2-butanol & $1.60 \pm 0.09$ & $5.78 \pm 1.01$ & \\
\hline & & $1.57 \pm 0.08$ & $5.65 \pm 1.00$ & \\
\hline & & $1.61 \pm 0.09$ & $5.79 \pm 1.02$ & \\
\hline \multirow{6}{*}{$3,3 \mathrm{DM} 2 \mathrm{BuOH}+\mathrm{OH}$} & Isopropanol & $2.33 \pm 0.09$ & $11.90 \pm 0.48$ & $10.50 \pm 0.25$ \\
\hline & & $2.05 \pm 0.08$ & $10.50 \pm 0.45$ & \\
\hline & & $1.95 \pm 0.08$ & $9.95 \pm 0.43$ & \\
\hline & 2-Methyl-2-butanol & $2.39 \pm 0.09$ & $8.61 \pm 1.50$ & \\
\hline & & $2.92 \pm 0.09$ & $10.50 \pm 1.78$ & \\
\hline & & $2.25 \pm 0.09$ & $8.12 \pm 1.34$ & \\
\hline \multirow[t]{6}{*}{$4 \mathrm{MCHexOH}+\mathrm{OH}$} & Propene & $0.64 \pm 0.01$ & $17.10 \pm 2.59$ & $18.70 \pm 1.42$ \\
\hline & & $0.76 \pm 0.03$ & $20.30 \pm 3.19$ & \\
\hline & & $0.76 \pm 0.02$ & $20.40 \pm 3.10$ & \\
\hline & Cyclohexene & $0.27 \pm 0.01$ & $18.20 \pm 4.55$ & \\
\hline & & $0.27 \pm 0.01$ & $18.40 \pm 4.62$ & \\
\hline & & $0.27 \pm 0.01$ & $18.00 \pm 4.46$ & \\
\hline Reaction & Reference & $\left(k_{\mathrm{SA}} / k_{\mathrm{R}}\right) \pm 2 \sigma$ & $\left(k_{\mathrm{SA}} \pm 2 \sigma\right)^{\mathrm{a}} / 10^{-15}$ & $\left(\bar{k}_{\mathrm{SA}} \pm 2 \sigma\right)^{\mathrm{b}} / 10^{-15}$ \\
\hline \multirow[t]{6}{*}{$4 \mathrm{MCHexOH}+\mathrm{NO}_{3}$} & 1-Butanol & $1.08 \pm 0.12$ & $3.39 \pm 1.11$ & $2.69 \pm 0.37$ \\
\hline & & $1.81 \pm 0.15$ & $5.70 \pm 1.82$ & \\
\hline & & $0.79 \pm 0.07$ & $2.51 \pm 0.80$ & \\
\hline & 2-Ethyl-1-hexanol & $0.71 \pm 0.10$ & $2.08 \pm 0.72$ & \\
\hline & & $1.00 \pm 0.10$ & $2.93 \pm 0.96$ & \\
\hline & & $0.86 \pm 0.08$ & $2.52 \pm 0.82$ & \\
\hline
\end{tabular}

a The uncertainties for rate coefficients of SAs $\left(\sigma_{\mathrm{SA}}\right)$ were calculated from the uncertainty of the slope of plots $\left(\sigma_{\mathrm{slope}}\right)$ and the uncertainty of the reference $\left(\sigma_{\mathrm{kR}}\right)$ using the propagation of uncertainties. ${ }^{\mathrm{b}}$ The weighted average according to the equation $\left(w_{1} k_{1}+w_{2} k_{2}+\ldots\right) /\left(w_{1}+w_{2} \ldots\right)$; $\left(w_{i}=1 / \sigma_{l}^{2}\right)$. The uncertainty of the weighted average $(\sigma)$ was given by $\left(1 / w_{1}+1 / w_{2}+\ldots\right)^{-0.5}$. 
(a)
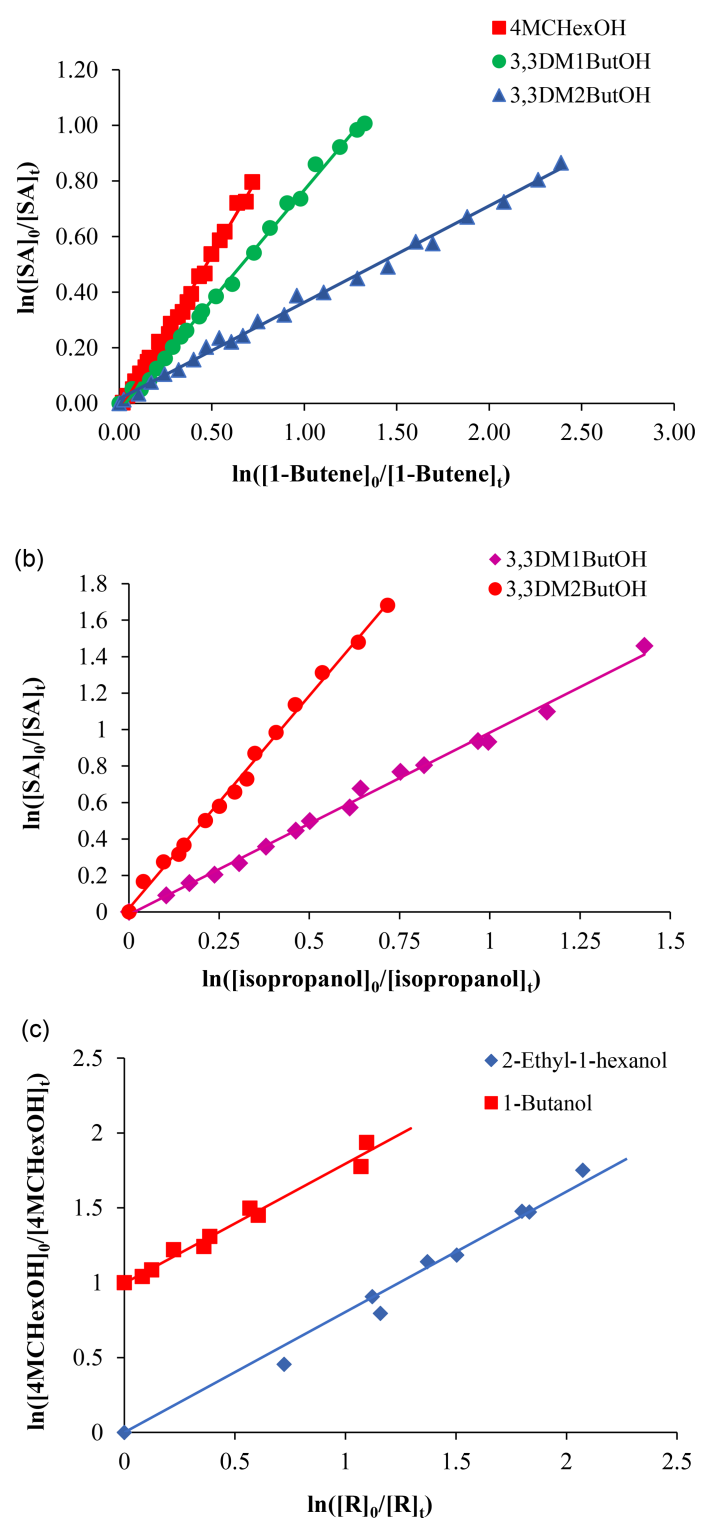

Figure 1. Relative rate plots for the reaction of (a) SAs with chlorine atoms, employing 1-butene as a reference compound; (b) 3,3dimethylbutanol and the $\mathrm{OH}$ radical with isopropanol as a reference compound; and (c) $4 \mathrm{MCHexOH}$ and $\mathrm{NO}_{3}$ with two reference compounds. Data for 1-butanol have been vertically displaced for clarity.

mann and Atkinson, 2012). The presence of the $\mathrm{OH}$ group in saturated alcohols implies two types of hydrogens that can be abstracted: hydrogen bonded to a carbon $(\mathrm{C}-\mathrm{H})$ of the main chain or of an alkyl substituent, and hydrogen bonded to an oxygen of the $\mathrm{OH}$ group. Two literature reviews of the reactivity of saturated alcohols (Calvert et al., 2011; Mellouki et al., 2015) conclude that (1) the reactions of aliphatic alcohols with atmospheric oxidants proceed mainly by $\mathrm{H}$ atom abstraction from various $\mathrm{C}-\mathrm{H}$ groups in the alkyl chain, with the abstraction of the $\mathrm{H}$ atom from the $\mathrm{O}-\mathrm{H}$ group being negligible; (2) rate coefficients for the reactions of $\mathrm{Cl}, \mathrm{OH}$, and $\mathrm{NO}_{3}$ are higher for alcohols than those of the corresponding alkanes due to the activating effect of the $\mathrm{OH}$ group, with this effect extending over about four carbon atoms (Nelson et al., 1990); and (3) the attack percentage of a radical to the different sites of the alcohol $(\alpha, \beta, \gamma$, and $\delta$ ) depends on the oxidant, the structure of saturated alcohol, the type and numbers of substituents, and temperature (Moreno et al., 2012, 2014; McGillen et al., 2013, 2016).

In order to verify these remarks, the reactivity of the SAs studied in this work were analyzed and discussed by comparing the rate coefficients of the SAs obtained with different oxidants, by comparing the rate coefficients of the SAs and the rate coefficients of their homologous alkanes available in literature, and by comparing the rate coefficients obtained in the reaction of the same oxidant but with different alcohols. The data used in the comparison are summarized in Table S1 in the Supplement.

From the analysis of all of the data shown in Table S1, the following can be observed:

a. The trend in the reactivity of SAs in relation to the different oxidants is the same that observed for other saturated alcohols: $k_{\mathrm{Cl}}\left(\mathrm{k} \approx 10^{-10}\right)>k_{\mathrm{OH}}\left(k \approx 10^{-11}\right) \gg$ $k_{\mathrm{NO}_{3}}\left(k \approx 10^{-15}\right)\left(k\right.$ is shown in $\mathrm{cm}^{3}$ molecule $\left.{ }^{-1} \mathrm{~s}^{-1}\right)$. This behavior could be explained by considering the geometry and electronic density of each oxidant, along with kinetic collision theory. As the $\mathrm{Cl}$ atom has a spherical electronic density distribution, any collision orientation is suitable; in addition, the $\mathrm{Cl}$ atoms present low steric hindrance. Therefore, the $\mathrm{Cl}$ reaction is comparatively less selective and faster, with values for the rate coefficient, $k$, in the collision limit. However, the $\mathrm{OH}$ radical presents an asymmetrical electron density located mostly over its oxygen atom. Therefore, for the $\mathrm{OH}$ reaction the oxygen of the $\mathrm{OH}$ radical must be specifically oriented toward the hydrogen of the SA that will be abstracted. The electronic density of the nitrate radical is distributed around the three oxygens, which implies several appropriate orientations, but as the nitrate radical has a nonlinear structure, the steric hindrance is much greater than for the $\mathrm{OH}$ radical, which reduces the reactivity of $\mathrm{NO}_{3}$ in relation to that of $\mathrm{OH}$.

b. The rate coefficient for the reaction of $4 \mathrm{MCHexOH}$ with $\mathrm{Cl}$ atoms is similar to the rate coefficient of its homologous alkane ((E)-1,4dimethylcyclohexane): $\quad k_{4 \mathrm{MCHexOH}+\mathrm{Cl}}=37.0 \times$ $10^{-11} \approx k_{(\mathrm{E})-1,4-\text { dimethylcyclohexane }+\mathrm{Cl}}=36.3 \times$ $10^{-11}$. In the case of the reaction with $\mathrm{OH}$ radical, the rate coefficient of $4 \mathrm{MCHexOH}$ is 1.5 times higher than with (E)-1,4-dimethylcyclohexane: $k_{4 \mathrm{MCHexOH}+\mathrm{OH}}=$ $18.7 \times 10^{-12}>k_{(\mathrm{E})-1,4-\text { dimethylcyclohexane }+\mathrm{OH}}=$ $12.1 \times 10^{-12}$ (Table S1). These results show that the activating effect of the $\mathrm{OH}$ group of the SA is less 
important for the reaction with $\mathrm{Cl}$ atoms than with the $\mathrm{OH}$ radical, which is behavior that agrees with that established by the structure-activity relationship (SAR) methods (Kwok and Atkinson, 1995; Calvert et al., 2011). There are no rate coefficient data for the reactions with the $\mathrm{NO}_{3}$ radical of the alkanes homologous to the SAs studied in this work; therefore, it was not possible to check the effect of the $\mathrm{OH}$ group in the reaction with $\mathrm{NO}_{3}$. However, according to the SAR method developed by Kerdouci et al. (2010) for the reactions of alcohols with $\mathrm{NO}_{3}$, this effect is greater than in the corresponding $\mathrm{Cl}$ and $\mathrm{OH}$ reactions.

c. The activating effect of the chain length in the reactivity of alcohols is also different for the $\mathrm{Cl}$ and $\mathrm{OH}$ reactions (see Table $\mathrm{S} 1$ ). Furthermore, if the rate coefficients of 3-methyl-1-butanol (3M1ButOH) and 3,3DM1ButOH with $\mathrm{Cl}$ and $\mathrm{OH}$ are compared, a slight increase in the rate coefficient for $\mathrm{Cl}$ reaction can be observed $\left(k_{3 \mathrm{M} 1 \mathrm{BuOH}+\mathrm{Cl}}=25.0 \times 10^{-11}\right.$; $\left.k_{3,3 \mathrm{DM} 1 \mathrm{ButOH}+\mathrm{Cl}}=26.9 \times 10^{-11}\right)$ along with an important decrease in the rate coefficient for the $\mathrm{OH}$ reactions $\left(k_{3 \mathrm{M} 1 \mathrm{BuOH}+\mathrm{OH}}=14 \times 10^{-12} ; k_{3,3 \mathrm{DM} 1 \mathrm{ButOH}+\mathrm{OH}}=\right.$ $5.33 \times 10^{-12}$ ). This behavior could be explained by the different order of reactivity of the two oxidants. Thus, for the $\mathrm{Cl}$ atom, which is more reactive ( $k$ of the order of $10^{-10} \mathrm{~cm}^{3}$ molecule $\mathrm{s}^{-1} \mathrm{~s}^{-1}$ ) but less selective than $\mathrm{OH}$, an increase in the chain length or in the number of methyl groups in the SA implies more hydrogens available to be abstracted and, therefore, an increase in the rate coefficient. However, for the $\mathrm{OH}$ radical, which is less reactive ( $k$ of the order of $10^{-11}$ $10^{-12} \mathrm{~cm}^{3}$ molecule ${ }^{-1} \mathrm{~s}^{-1}$ ) and more selective than $\mathrm{Cl}$, the attack for $\mathrm{H}$ abstraction will be carried out at a specific position in the SA, so an increase in the chain length of the alcohol does not have a significant effect on the reactivity; the presence of a second methyl group even disfavors the reaction, probably due to steric hindrance near the attack position.

In addition, as can be seen in Table S1, the position of the $\mathrm{OH}$ group of SA has a different effect on the reactivity depending on the oxidant. In the case of the $\mathrm{Cl}$ atom reactions, the rate coefficients for primary alcohols (1-propanol, 1butanol, 1-pentanol, 3-methyl-1-butanol, and 3,3-dimethyl1-butanol) are higher than the those of secondary alcohols (2-propanol, 2-butanol, 2-pentanol, 3-methyl-2-butanol, and 3,3-dimethyl-2-butanol) contrary to the $\mathrm{OH}$ and $\mathrm{NO}_{3}$ radical reactions. This indicates that the formation of the most stable radical seems to have less importance with respect to the reactivity than the number of hydrogens in the $\alpha$-position available to be abstracted in the reaction of $\mathrm{Cl}$ atoms.

All of these observations could imply a different mechanism for the $\mathrm{H}$-abstraction process for $\mathrm{Cl}$ atoms than for $\mathrm{OH}$ radicals. Nelson et al. (1990) and Smith and Ravishankara (2002) indicate the possible formation of an inter- mediate adduct between the $\mathrm{OH}$ radical and the oxygen of the $\mathrm{OH}$ group that will imply a specific orientation. Theoretical studies found in the literature show this different $\mathrm{H}$ abstraction process in the reaction of saturated alcohols with $\mathrm{Cl}$ atoms (Garzon et al., 2006) and $\mathrm{OH}$ radicals (Moc and Simmie, 2010). There are insufficient rate coefficient data to establish conclusions about the mechanism for the reaction of SAs with $\mathrm{NO}_{3}$ radicals. Different mechanisms in the hydrogen atom abstraction process for each oxidant will imply different product distributions and molecular yields, as will be shown in Sect. 3.2.

\section{Estimation of rate coefficients}

In order to estimate the rate coefficients of the reactions of organic compounds with the atmospheric oxidants, a multitude of methods have been proposed (Vereecken et al., 2018). The most popular and widely used is the SAR method that was initially developed by Kwok and Atkinson (1995) to estimate the rate coefficients for gas-phase reactions with the $\mathrm{OH}$ radical at room temperature. This method has been updated for $\mathrm{OH}$ reactions (Jenkin et al., 2018) and extended to reaction with $\mathrm{NO}_{3}$ (Kerdouci et al., 2010, 2014) and $\mathrm{Cl}$ (Calvert et al., 2011; Poutsma 2013). The US EPA (United States Environmental Protection Agency) has developed the EPI Suite ${ }^{\mathrm{TM}}$-Estimation Program Interface that allows for the estimation of the rate coefficients for the reactions of the $\mathrm{OH}$ radical with organic compounds using the AOPWIN program (v1.92).

In our work, the rate coefficients of SAs with the three oxidants have been estimated using the SAR method (see Sect. S2 in the Supplement). The results are shown in Table 2. The estimated values of the rate coefficients agree with experimental data, with $k_{\text {exp }} / k_{\text {SAR }}$ ratios between 0.9 and 1.28 , except for the case of 3,3DM1ButOH and the $\mathrm{NO}_{3}$ radical, which showed a $k_{\exp } / k_{\mathrm{SAR}}$ ratio of 3.24 . In general, the SAR method when applied to alcohols predicts better rate coefficients for the $\mathrm{Cl}$ atom and the $\mathrm{OH}$ radical than for the $\mathrm{NO}_{3}$ radical, especially for primary alcohols. It is important to note that the kinetic database for the $\mathrm{NO}_{3}$ reactions is more limited than for $\mathrm{Cl}$ and $\mathrm{OH}$ reactions, so the estimated rate coefficient for the $\mathrm{NO}_{3}$ radical should be treated with caution (Kerdouci et al. 2010, 2014; Calvert et al., 2011).

It is known that organic compounds that react in the same way with different atmospheric oxidants present a correlation between their rate coefficients. In this sense, over the years, different correlations have been proposed to allow the estimation of the unknown rate coefficient when the other is known (Wayne et al., 1991; Wayne, 2000; Atkinson, 1994; Calvert et al., 2011; Gallego-Iniesta et al., 2014). The $\log k_{\mathrm{Cl}}-\log k_{\mathrm{OH}}$ and $\log k_{\mathrm{NO}_{3}}-\log k_{\mathrm{OH}}$ correlations have been built for a set of ethers and saturated alcohols by Calvert et 
Table 2. Estimated and experimental rate coefficients $\left(k_{\mathrm{SAR}}, k_{\mathrm{log}}\right.$, and $\left.k_{\mathrm{exp}}\right)$ for the reaction of SAs with atmospheric oxidants and the ratio of rate coefficients $\left(k_{\exp } / k_{\mathrm{SAR}}\right.$ and $\left.k_{\exp } / k_{\mathrm{log}}\right) \cdot k_{\mathrm{Cl}} / 10^{-11}, k_{\mathrm{OH}} / 10^{-12}$, and $k_{\mathrm{NO}_{3}} / 10^{-15}$ are shown in cubed centimeters per molecule per second $\left(\mathrm{cm}^{3}\right.$ molecule $\left.\mathrm{s}^{-1}\right)$.

\begin{tabular}{lrrr|rrr|rrr}
\hline & \multicolumn{3}{c}{$4 \mathrm{MCHexOH}$} & \multicolumn{3}{c|}{$3,3 \mathrm{DM} 1 \mathrm{ButOH}$} & \multicolumn{3}{c}{$3,3 \mathrm{DM} 2 \mathrm{ButOH}$} \\
\cline { 2 - 10 } & $k_{\mathrm{Cl}}$ & $k_{\mathrm{OH}}$ & $k_{\mathrm{NO}_{3}}$ & $k_{\mathrm{Cl}}$ & $k_{\mathrm{OH}}$ & $k_{\mathrm{NO}_{3}}$ & $k_{\mathrm{Cl}}$ & $k_{\mathrm{OH}}$ & $k_{\mathrm{NO}_{3}}$ \\
\hline$k_{\exp }$ & $37.0^{\mathrm{a}}$ & $18.7^{\mathrm{a}}$ & $2.69^{\mathrm{a}}$ & $26.9^{\mathrm{a}}$ & $5.33^{\mathrm{a}}$ & $1.78^{\mathrm{b}}$ & $12.1^{\mathrm{a}}$ & $10.5^{\mathrm{a}}$ & $3.4^{\mathrm{b}}$ \\
$k_{\mathrm{SAR}}$ & $34.2^{\mathrm{c}}$ & $19.2^{\mathrm{c}}$ & $2.27^{\mathrm{c}}$ & $21.0^{\mathrm{c}}$ & $6.08^{\mathrm{c}}$ & $0.55^{\mathrm{c}}$ & $15.2^{\mathrm{c}}$ & $9.16^{\mathrm{c}}$ & $3.86^{\mathrm{c}}$ \\
$k_{\exp } / k_{\mathrm{SAR}}$ & 1.08 & 0.97 & 1.18 & 1.28 & 0.88 & 3.24 & 0.80 & 1.15 & 0.88 \\
$k_{\log }$ & $30.7^{\mathrm{d}}$ & - & $4.69^{\mathrm{d}}$ & $13.9^{\mathrm{d}}$ & - & $1.16^{\mathrm{d}}$ & $21.4^{\mathrm{d}}$ & - & $3.19^{\mathrm{d}}$ \\
$k_{\exp } / k_{\log }$ & 1.21 & - & 0.57 & 1.94 & - & 1.53 & 0.57 & - & 1.07 \\
\hline
\end{tabular}

${ }^{a}$ Data obtained in this work. ${ }^{b}$ Data obtained by Moreno et al. (2014). ${ }^{\mathrm{c}}$ See S2. ${ }^{\mathrm{d}}$ Estimated using the correlations $\log _{\mathrm{Cl}}-\log _{\mathrm{OH}}$ (Eq. 2) and $\log _{\mathrm{NO}_{3}}-\log _{\mathrm{OH}}$ (Eq. 3) described by Calvert et al. (2011).

al. (2011), obtaining the following relationships:

$$
\begin{aligned}
& \log \left(k_{\mathrm{Cl}} / \mathrm{cm}^{3} \text { molecule } \mathrm{s}^{-1}\right)=0.634 \\
& \quad \times \log \left(k_{\mathrm{OH}} / \mathrm{cm}^{3} \text { molecule }^{-1} \mathrm{~s}^{-1}\right)-2.71 \\
& \quad\left(r^{2}=0.72\right) ; \\
& \log \left(k_{\mathrm{NO}_{3}} / \mathrm{cm}^{3} \text { molecule }^{-1} \mathrm{~s}^{-1}\right)=1.11 \\
& \quad \times \log \left(k_{\mathrm{OH}} / \mathrm{cm}^{3} \text { molecule }^{-1} \mathrm{~s}^{-1}\right)-2.42 \\
& \left(r^{2}=0.66\right) .
\end{aligned}
$$

These equations have been used to estimate the rate coefficients of the reactions of SAs with $\mathrm{Cl}$ and the $\mathrm{NO}_{3}$ radical using the experimental rate coefficients measured in this work for $\mathrm{OH}$ reactions. The estimated rate coefficients, $k_{\log }$, according to Eqs. (2) and (3), and the ratios $\left(k_{\exp } / k_{\log }\right)$, are also shown in Table 2 . This estimation method obtains a slightly better rate coefficient for the 3,3DM1ButOH $+\mathrm{NO}_{3}$ reaction $\left(k_{\exp } / k_{\log }=1.53\right)$ than the SAR method $\left(k_{\exp } / k_{\mathrm{SAR}}=3.24\right)$. However, for $\mathrm{Cl}$ reactions, the $k_{\exp } / k_{\log }$ ratios are in the range of 0.6-1.97, indicating that Eq. (2) predicts rate coefficients worse than SAR method. Again, this could be due to the different reaction mechanism in the $\mathrm{H}$-abstraction process for the $\mathrm{Cl}$ and $\mathrm{OH}$ reactions. It is important to indicate that in the case of $\mathrm{Cl}$ reactions, other effects, such as thermochemistry and the polar effect, must be considered to estimate the rate coefficients for H-abstraction reactions (Poutsma, 2013).

\subsection{Product and mechanistic study}

A product study of the reaction of $4 \mathrm{MCHexOH}$, 3,3DM1ButOH, and 3,3DM2ButOH with $\mathrm{Cl}$ atoms in the absence/presence of $\mathrm{NO}_{x}$, hydroxyl, and nitrate radicals has been performed. IR absorption bands of $\mathrm{HCl}, \mathrm{CO}_{2}, \mathrm{CO}$, $\mathrm{HNO}_{3}, \mathrm{~N}_{2} \mathrm{O}, \mathrm{NO}_{2}, \mathrm{HCOOH}, \mathrm{HCOH}, \mathrm{ClNO}, \mathrm{ClNO}_{2}$, and $\mathrm{CH}_{3} \mathrm{NO}_{3}$ were observed in the FTIR experiments. Some of these compounds are products from the reactions of the SAs with oxidants. They can also be formed by the decomposition of the employed precursors $\left(\mathrm{Cl}_{2}, \mathrm{CH}_{3} \mathrm{ONO}\right.$, and $\mathrm{N}_{2} \mathrm{O}_{5}$ ) and in some cases, by heterogeneous reactions of these precursors with the Pyrex glass reactor walls. The formation of $\mathrm{O}_{3}$ and $\mathrm{N}_{2} \mathrm{O}_{5}$ have also been observed after long reaction times for the reactions of the SAs with $\mathrm{Cl}$ atoms in the presence of $\mathrm{NO}_{x}$, due to the high concentration of $\mathrm{NO}_{2}$ in the reaction medium and the presence of radiation. Quantitative analysis was carried out by linear subtraction of a spectrum's absorption bands and the peak areas of GC chromatograms using the calibrated spectra and reference chromatograms.

The experimental conditions and molecular yields of the main products formed in the reactions of SAs and analyzed by FTIR and SPME/GC-TOFMS are given in Tables 3-6. Molecular yields could be affected by large errors associated with the SPME sampling method and due to the presence of interfering IR absorption bands, mainly associated with precursors of the $\mathrm{OH}$ and $\mathrm{NO}_{3}$ radicals or by the nitrated compounds formed.

\subsubsection{MCHexOH}

(E)-4-methylcyclohexanone was identified in the reactions with $\mathrm{Cl}$ (in the absence/presence of $\mathrm{NO}_{x}$ ), $\mathrm{OH}$, and $\mathrm{NO}_{3}$. An example of the product spectra obtained by FTIR is shown in Fig. 2. Formation of (E)-4-methylcyclohexanone was confirmed by introducing a sample of the commercial product (spectrum (e)). A set of experiments using the SPME as the sampling method and the GC-TOFMS as the detection technique were also carried out for the reactions of $4 \mathrm{MCHexOH}$ with $\mathrm{Cl}$ atoms and with the respective $\mathrm{OH}$ and $\mathrm{NO}_{3}$ radicals. An example of the chromatogram obtained for the reaction of $4 \mathrm{MCHexOH}$ with $\mathrm{Cl}$ atoms is shown in Fig. 3. In all of the studied reactions, the formation of a product peak at 10.35 min was observed. The peak (b) shown in Fig. 3 was assigned to (E)-4-methylcyclohexanone and confirmed by comparing it with the retention time and MS of a commercial sample. In the reactions with $\mathrm{Cl}$ atoms (in the ab- 
Table 3. Experimental conditions and molecular yields of (E)-4-methylcyclohexanone for the reaction of $4 \mathrm{MCHexOH}$ with atmospheric oxidants.

\begin{tabular}{|c|c|c|c|c|c|c|c|c|c|}
\hline SA & Oxidant & Experiment & $\begin{array}{r}\text { [SA] } \\
(\mathrm{ppm})\end{array}$ & $\begin{array}{r}\text { [Precursor] } \\
(\mathrm{ppm})\end{array}$ & $\begin{array}{r}{[\mathrm{NO}]} \\
(\mathrm{ppm})\end{array}$ & $\begin{array}{r}\text { Carbonyl } \\
\text { compound } \\
\text { yield }^{\mathrm{d}}(\%)\end{array}$ & Technique & $\begin{array}{r}\text { Average }^{\mathrm{f}} \\
(\%)\end{array}$ & $\begin{array}{r}\text { SAR yield } \\
(\%)\end{array}$ \\
\hline \multirow[t]{15}{*}{$4 \mathrm{MCHexOH}$} & \multirow[t]{3}{*}{$\mathrm{Cl}^{\mathrm{a}}$} & 1 & 3 & 21 & - & $24.8 \pm 0.9$ & FTIR & \multirow[t]{3}{*}{$25.2 \pm 1.9$} & \multirow[t]{6}{*}{14} \\
\hline & & 2 & 8 & 22 & - & $23.8 \pm 0.6$ & FTIR & & \\
\hline & & 3 & 13 & 16 & - & $27.5 \pm 0.2$ & SPME/GC-TOFMS ${ }^{\mathrm{e}}$ & & \\
\hline & \multirow[t]{3}{*}{$\mathrm{Cl}^{\mathrm{a}}+\mathrm{NO}$} & 1 & 11 & 23 & 30 & $30.4 \pm 0.9$ & FTIR & \multirow[t]{3}{*}{$29.5 \pm 0.7$} & \\
\hline & & 2 & 5 & 25 & 19 & $30.0 \pm 0.6$ & FTIR & & \\
\hline & & 3 & 7 & 13 & 12 & $31.6 \pm 1.3$ & SPME/GC-TOFMS & & \\
\hline & \multirow[t]{4}{*}{$\mathrm{OH}^{\mathrm{b}}$} & 1 & 7 & 36 & 23 & $35.1 \pm 1.3$ & FTIR & \multirow[t]{4}{*}{$40.2 \pm 5.4$} & \multirow[t]{4}{*}{53} \\
\hline & & 2 & 13 & 31 & 29 & $38.2 \pm 1.5$ & FTIR & & \\
\hline & & 3 & 11 & 28 & 28.5 & $47.8 \pm 0.4$ & FTIR & & \\
\hline & & 4 & 6 & 19 & 12 & $39.8 \pm 0.9$ & SPME/GC-TOFMS & & \\
\hline & \multirow[t]{5}{*}{$\mathrm{NO}_{3}^{\mathrm{c}}$} & 1 & 3 & 6 & - & $56.8 \pm 11.4$ & SPME/GC-TOFMS & \multirow[t]{5}{*}{$58.0 \pm 23.5$} & \multirow[t]{5}{*}{86} \\
\hline & & 2 & 6 & 34 & - & $88.3 \pm 7.0$ & SPME/GC-TOFMS & & \\
\hline & & 3 & 4 & 30 & - & $77.1 \pm 4.6$ & SPME/GC-TOFMS & & \\
\hline & & 4 & 4 & 21 & - & $34.6 \pm 0.5$ & FTIR & & \\
\hline & & 5 & 7 & 10 & - & $33.4 \pm 0.6$ & FTIR & & \\
\hline
\end{tabular}

\footnotetext{
a Rate coefficient of $k=11.2 \times 10^{-11}$ (in $\mathrm{cm}^{3}$ molecule ${ }^{-1} \mathrm{~s}^{-1}$ ) used to correct the concentration of (E)-4-methylcyclohexanone by loss with the reaction of $\mathrm{Cl}$ atoms (data of 2-methylcyclohexanone and $\mathrm{Cl}$ atoms Herath et al., 2018). Photolysis rate coefficient estimated for (E)-4-methylcyclohexanone under our experimental conditions, $k_{\mathrm{p}}=5 \times 10^{-5} \mathrm{~s}^{-1}$. ${ }^{\mathrm{b}}$ Rate coefficient of $k=13.7 \times 10^{-12}$ (in $\mathrm{cm}^{3}$ molecule ${ }^{-1} \mathrm{~s}^{-1}$ ) used to correct the concentration of (E)-4-methylcyclohexanone by loss with the reaction of OH radicals (estimated using AOPWIN, v1.92). Photolysis rate coefficient estimated for (E)-4-methylcyclohexanone under our experimental conditions, $k_{\mathrm{p}}=5 \times 10^{-5} \mathrm{~s}^{-1}$. ${ }^{\mathrm{c}} \mathrm{Rate}$ coefficient of $k=2.28 \times 10^{-16}$ (in $\mathrm{cm}^{3}$ molecule $\mathrm{s}^{-1} \mathrm{~s}^{-1}$ ) used to correct the concentration of (E)-4-methylcyclohexanone by loss with the reaction of $\mathrm{NO}_{3}$ radicals (estimated using the SAR method, Kerdouci et al., 2014).

${ }^{\mathrm{d}}$ Indicated errors are the errors associated with the slope of plots obtained in the least squares analysis. ${ }^{\mathrm{e}}$ Experiment using a $150 \mathrm{~L}$ Teflon gas bag. ${ }^{\mathrm{f}}$ Standard deviations $1 \sigma$.
}

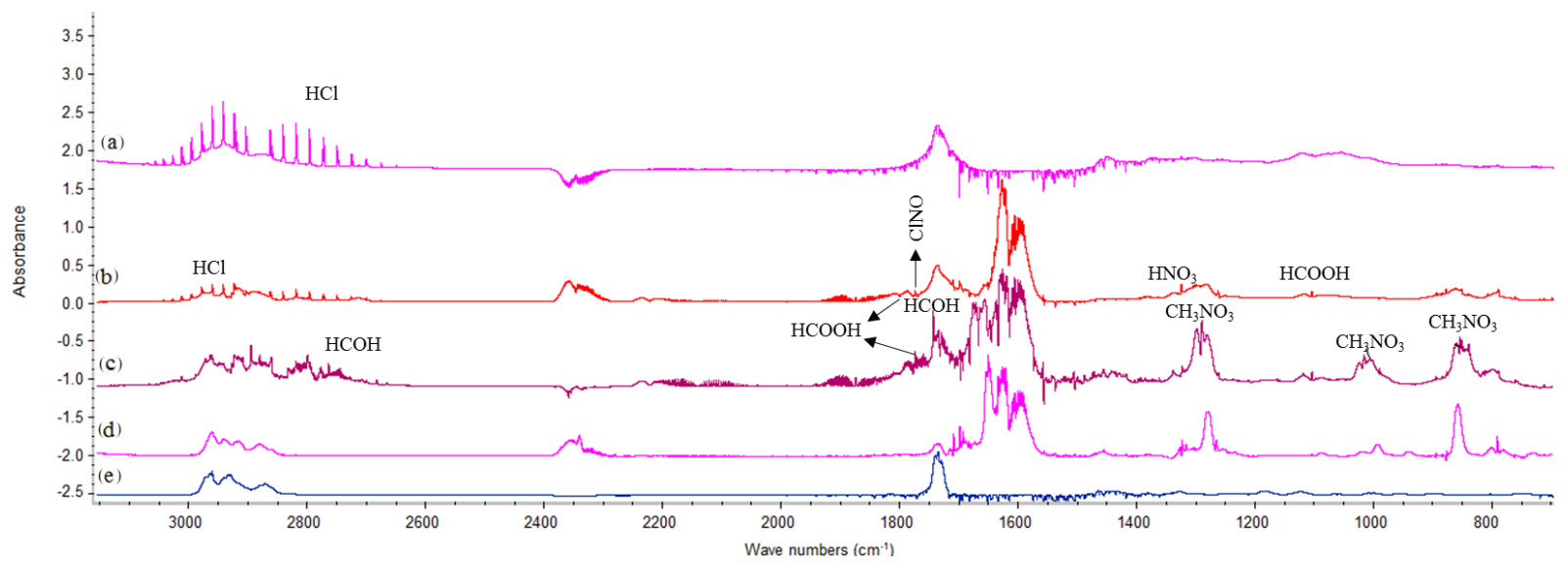

Figure 2. Product spectra for the reaction of $4 \mathrm{MCHexOH}$ with (a) chlorine atoms at $10 \mathrm{~min}$ ( $\times 2$ for clarity), (b) $\mathrm{Cl}$ atoms in the presence of $\mathrm{NO}_{x}$ at $7 \mathrm{~min}$, (c) the $\mathrm{OH}$ radical at $40 \mathrm{~min}$, and (d) the $\mathrm{NO}_{3}$ radical at $32 \mathrm{~min}$. (e) Spectrum of the 4-methylcyclohexanone commercial sample.

sence/presence of $\mathrm{NO}_{x}$ ) and the $\mathrm{OH}$ radical two additional peaks at 19.80 (c) and 20.25 min (d) were observed.

The time-concentration profiles of $4 \mathrm{MCHexOH}$ and (E)4-methylcyclohexanone obtained by FTIR analysis for the reaction with $\mathrm{Cl}$ atoms in the presence of $\mathrm{NO}_{x}$ are shown in Fig. S2. The concentrations of (E)-4-methylcyclohexanone, corrected according to Eqs. (S1), (S2), and (S3) in the Supplement were plotted against the amounts of $4 \mathrm{MCHexOH}$ consumed in order to obtain the yield of 4methylcyclohexanone from the slope. An example of the plots obtained is shown in Fig. 4. Molecular yields, $Y(\%)$, of (E)-4-methylcyclohexanone obtained in all experiments are listed in Table 3. Based on the average molecular yield of (E)-4-methylcyclohexanone, the carbon balance was below $50 \%$ for reactions with $\mathrm{Cl}$ and the $\mathrm{OH}$ radical and $\sim 60 \%$ for $\mathrm{NO}_{3}$.

Residual spectra after the subtraction of (E)-4methylcyclohexanone show IR absorption bands compatible with the presence of hydroxycarbonyl compounds $(\sim 1750$, 1720 , and $1060 \mathrm{~cm}^{-1}$ ) and nitrated organic compounds 


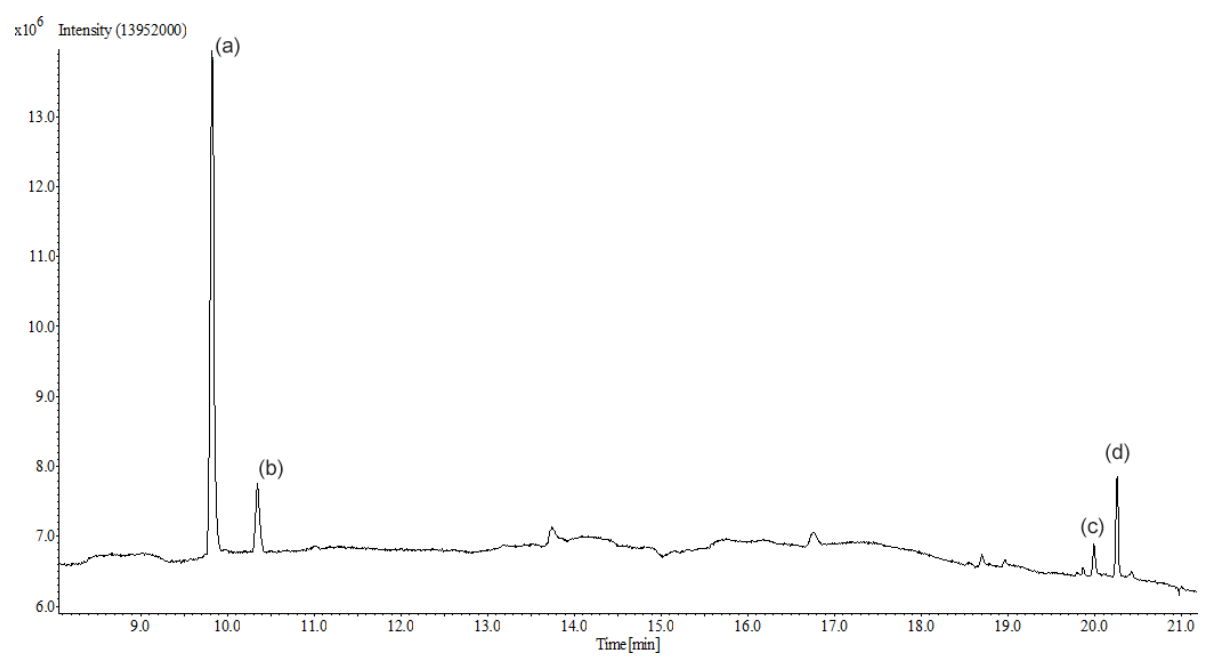

Figure 3. SPME/GC-TOFMS chromatogram for the reaction of $4 \mathrm{MCHexOH}$ with $\mathrm{Cl}$ atoms after 15 min of reaction. Peak (a) is $4 \mathrm{MCHexOH}$, peak (b) is (E)-4-methylcyclohexanone, and peaks (c) and (d) are reaction products.

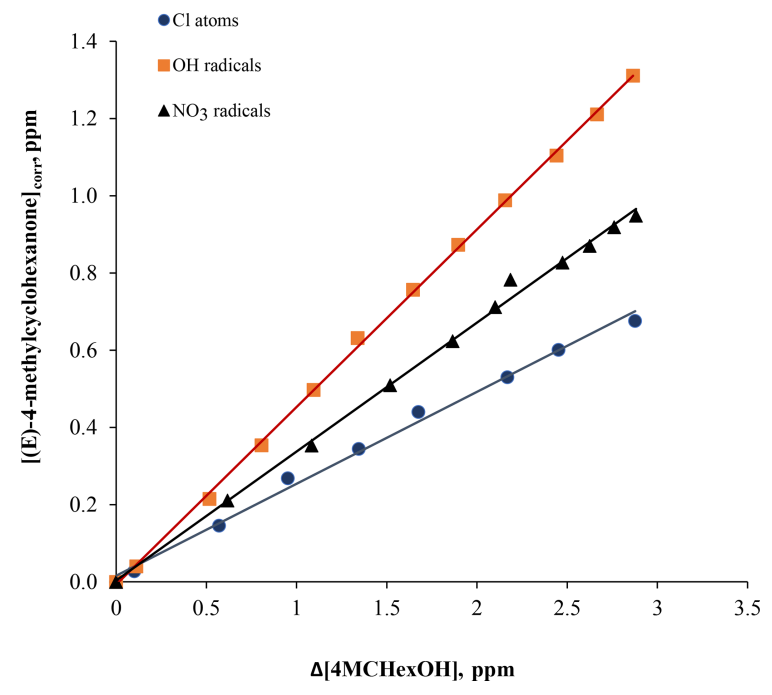

Figure 4. Plots of the corrected concentration of (E)-4methylcyclohexanone ([(E)-4-methylcyclohexanone $\left.]_{\text {corr }}\right)$ against $4 \mathrm{MCHexOH}$ consumed $(\triangle[4 \mathrm{MCHexOH}])$ for $\mathrm{Cl}$ atoms (in the absence of $\mathrm{NO}_{x}$ ) and $\mathrm{OH}$ and $\mathrm{NO}_{3}$ radical reactions.

$\left(\mathrm{RONO}_{2} \sim 1660,1264\right.$ and $862 \mathrm{~cm}^{-1}$, and/or $\mathrm{ROONO}_{2}$ $\sim 1720,1300$ and $760 \mathrm{~cm}^{-1}$ ); see the residual spectra in Fig. S3. The amount of nitrated compounds was estimated using the average integrated absorption coefficient of $1.2 \times 10^{-17} \mathrm{~cm}$ molecule ${ }^{-1}$ of similar compounds corresponding to the IR range from 1260 to $1305 \mathrm{~cm}^{-1}$ (Tuazon and Atkinson, 1990). The calculated yields of $\mathrm{RONO}_{2}$ were $20 \%$ and $60 \%$ for $\mathrm{Cl}$ (in the presence of $\mathrm{NO}_{x}$ ) and $\mathrm{NO}_{3}$ reactions, respectively. A yield of $10 \%$ of nitrated compounds was estimated for the reaction with the $\mathrm{OH}$ radical. This lower yield could be due to fact that the $\mathrm{NO}_{x}$ present in the reaction medium reacts faster with the $\mathrm{CH}_{3} \mathrm{O}$ radical, formed by photolysis of $\mathrm{CH}_{3} \mathrm{ONO}$, than other alkoxy radicals. Table 6 shows a summary of the average yields of reaction products quantified for $4 \mathrm{MCHexOH}$ reactions.

Considering the products detected here and those detected in the study of Bradley et al. (2001) relative to cyclohexanol with $\mathrm{OH}$ radical reactions, a degradation mechanism for $4 \mathrm{MCHexOH}$ with the atmospheric oxidants has been proposed. Figure 5a shows the paths that explain the formation of organic compounds (carbonyl, hydroxycarbonyl, etc.), and Fig. $5 b$ shows an example of a path to explain the formation of nitrated organic compounds $\left(\mathrm{ROONO}_{2}\right.$ and $\left.\mathrm{RONO}_{2}\right)$. Similar nitrated compounds could be formed by routes II-IV. The abstraction of the hydrogen atom at the $\alpha$-position with respect to the $\mathrm{OH}$ group (route I) followed by the addition of oxygen, the formation of a peroxy radical, and the fast decomposition of this radical explain the formation of (E)4-methylcyclohexanone. Based on the molecular yield obtained for (E)-4-methylcyclohexanone for each oxidant (see Table 6), this route represents $\sim 25 \% / 30 \%, \sim 40 \%$, and $\sim 60 \%$ of the reaction mechanism of $4 \mathrm{MCHexOH}$ with $\mathrm{Cl}$ (in the absence/presence of $\mathrm{NO}_{x}$ ), $\mathrm{OH}$ and $\mathrm{NO}_{3}$, respectively. Percentages are 2-fold higher than those predicted by the SAR method in the case of the $\mathrm{Cl}$ reactions and 1.3- and 1.5-fold lower for the $\mathrm{OH}$ and $\mathrm{NO}_{3}$ reactions, respectively. These data should be taken with caution, as they could include many sources of error.

Apart from (E)-4-methylcyclohexanone, other carbonyl and hydroxycarbonyl compounds could be formed by routes II, III, and IV. The presence of these types of compounds has been observed in the reactions with $\mathrm{Cl}$ and $\mathrm{OH}$. According to the electron ionization mass spectra (EIMS) (Fig. S4) an assignation of peaks (c) and (d) shown in Fig. 3, to 2-hydroxy-5-methylcyclohexanone, 5-hydroxy-2methylcyclohexanone, and/or 3-methyl-1,6-hexanedial has 
(a)

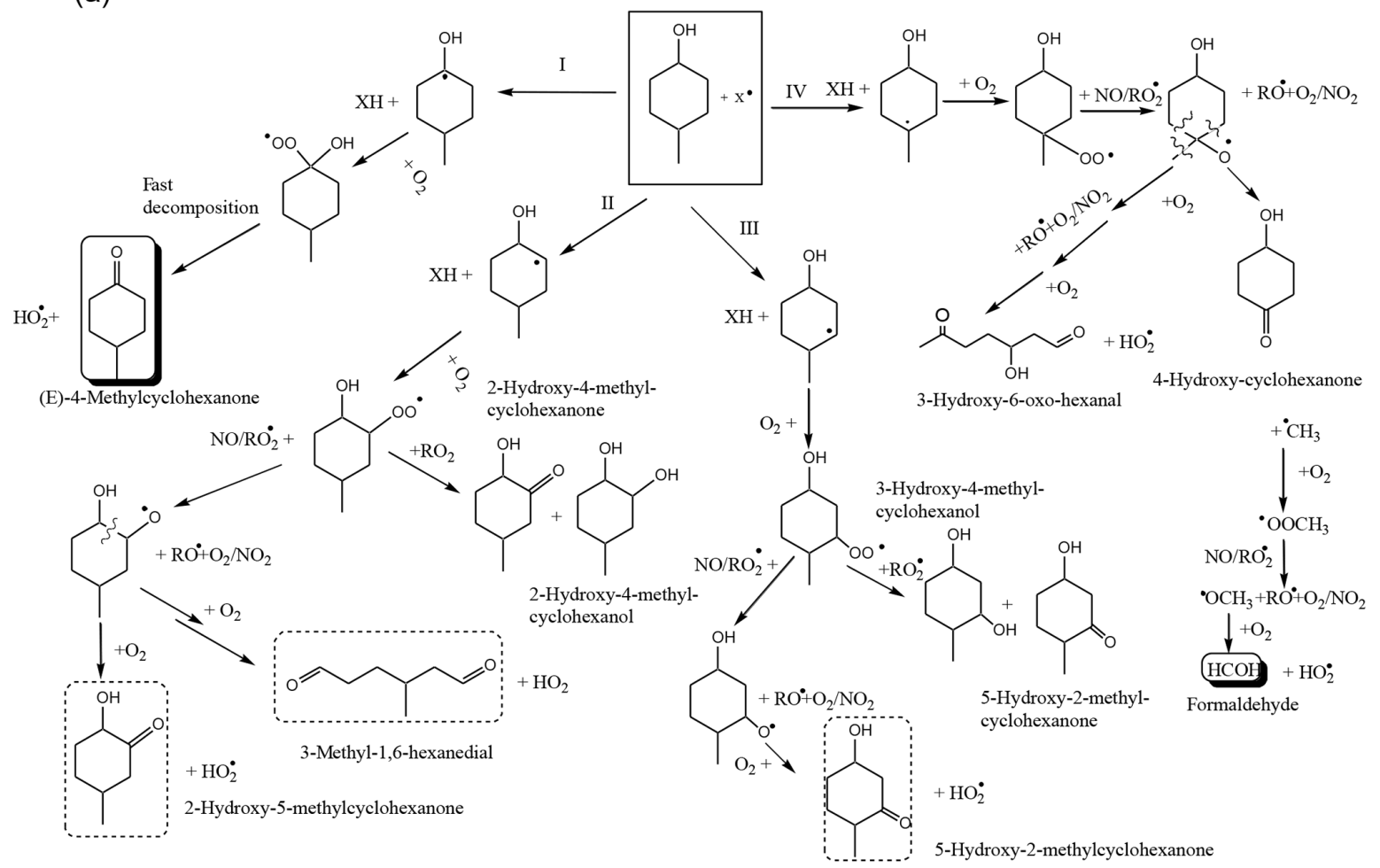

(b)

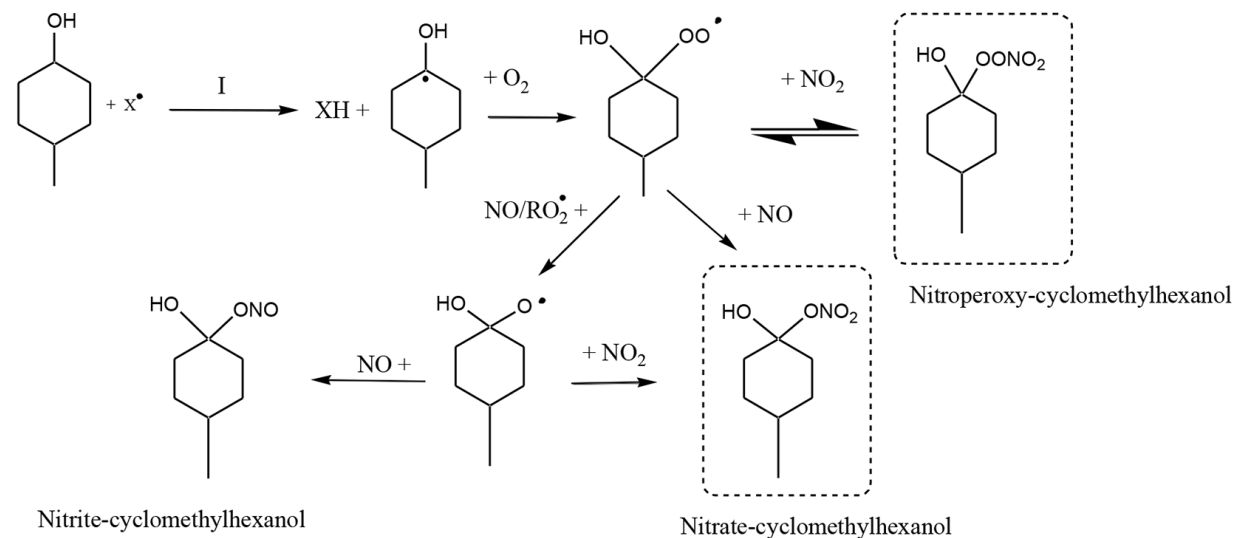

Figure 5. Reaction mechanism for the degradation of $4 \mathrm{MCHexOH}$ with $\mathrm{X}$ (the $\mathrm{Cl}$ atom and the $\mathrm{OH}$ and $\mathrm{NO}_{3}$ radicals). (a) The mechanism for the formation of carbonyl compounds. (b) The mechanism for the formation of nitrated compounds. Compounds marked with a solid line are positively identified. Compounds marked with a dotted line are not positively identified.

been proposed. However, according to the atmospheric reactivity (Finlayson and Pitts, 2000; Calvert et al., 2011; Ziemann and Atkinson, 2012) and the study of Bradley et al. (2001), the compound that would be expected is 3-methyl1,6-hexanedial, which arises from the decomposition of the alkoxy radical formed in route II. However, confirmation was not possible as these compounds are not commercially avail- able. The detection of about $9 \%$ of $\mathrm{HCOH}$ in the reaction with $\mathrm{Cl}$ atoms indicates that the elimination of the methyl group in route IV is minor.

In the case of nitrate radical, the only carbonyl compound detected was (E)-4-methylcyclohexanone, suggesting that route I may be the dominant pathway for this radical. The large difference between the yields of 
(a)

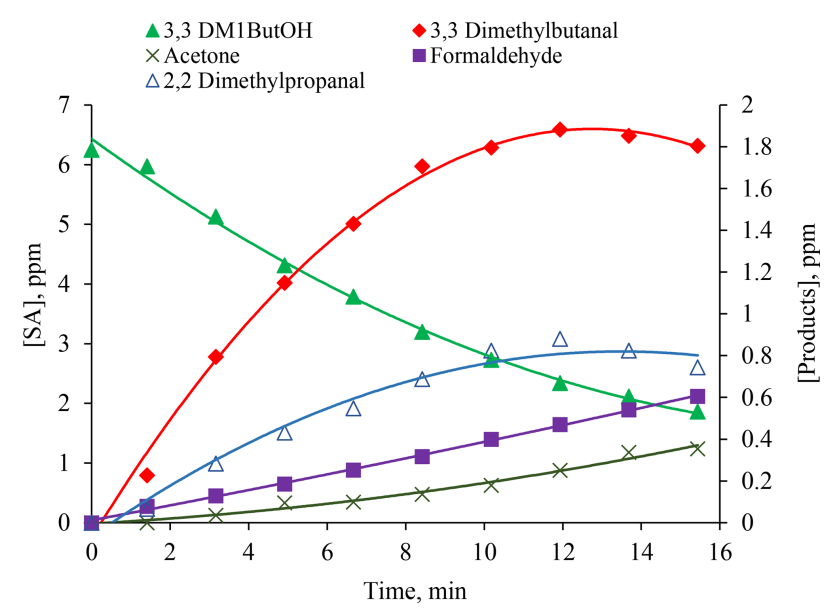

(b)

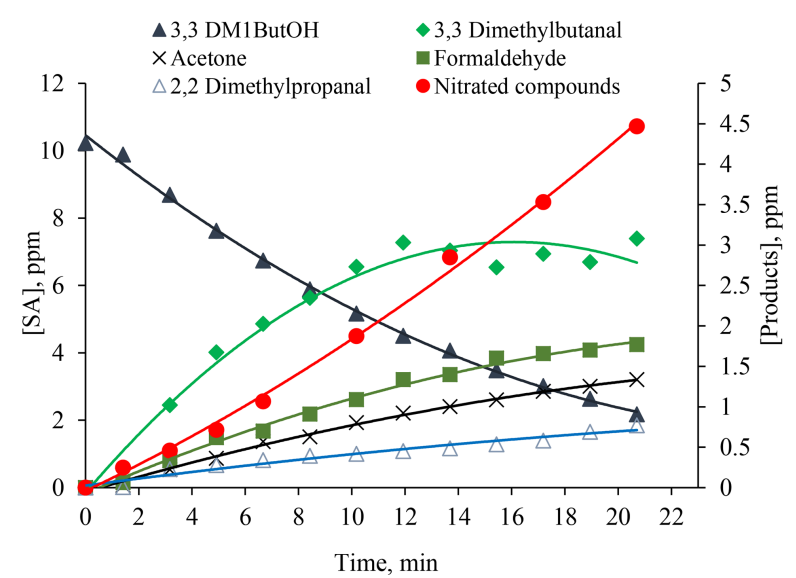

Figure 6. Concentration-time profiles of SA (3,3DM1ButOH) and reaction products formed in the reaction of $3,3 \mathrm{DM} 1 \mathrm{ButOH}$ with $\mathrm{Cl}$ atoms in the absence (a) and in the presence of $\mathrm{NO}_{x}$ (b).

(E)-4-methylcyclohexanone obtained using the SPME/GCTOFMS system $(\sim 75 \%)$ and the FTIR $(35 \%)$ could be due to the different methods of adding the precursor to the two reactors (small aliquots of $\mathrm{N}_{2} \mathrm{O}_{5}$ in the Teflon ${ }^{\circledR}$ reactor versus one large addition in the Pyrex ${ }^{\circledR}$ glass reactor). This procedure causes a lower initial concentration of nitrated inorganic species $\left(\mathrm{NO}_{3}, \mathrm{NO}_{2}\right.$, and $\left.\mathrm{HNO}_{3}\right)$ in the $150 \mathrm{~L}$ reactor than in the $50 \mathrm{~L}$ reactor, favoring the formation of carbonyl compounds instead of nitrated organic compounds. Taking the yields of (E)-4-methylcyclohexanone and the nitrated compounds for the $\mathrm{NO}_{3}$ reaction using FTIR analysis into account, a total carbon balance of $100 \%$ is obtained (see Table 6).

\subsubsection{3,3DM1ButOH}

For the reaction of $3,3 \mathrm{DM} 1 \mathrm{ButOH}$ with the three atmospheric oxidants, 3,3-dimethylbutanal was identified as the main reaction product. Figure S5a shows the FTIR spectra obtained for the reactions of 3,3DM1ButOH with $\mathrm{Cl}$ (in the absence/presence of $\mathrm{NO}_{x}$ ), $\mathrm{OH}$, and $\mathrm{NO}_{3}$. Residual FTIR spectra after the subtraction of 3,3-dimethylbutanal (Fig. S5b), the SPME/GC-TOFMS chromatograms (Fig. S6), and the EIMS spectra (Fig. S7), show that other reaction products such as carbonyl, hydroxycarbonyl, and nitrated compounds are formed. These reaction products could be formaldehyde, 2,2-dimethylpropanal, glycolaldehyde, acetone, and peroxy-3,3-dimethylbutyryl nitrate (P33DMBN) $\left(\mathrm{CH}_{3}\right)_{3} \mathrm{CCH}_{2} \mathrm{C}(\mathrm{O}) \mathrm{OONO}_{2}$. These compounds can be formed as primary products (see Fig. 6) and/or secondary products from the degradation of 3,3-dimethylbutanal (see Fig. S8). The SPME/GC-TOFMS chromatograms show common peaks for the three oxidants, but the numbers of peaks and their distribution are very different, especially for $\mathrm{OH}$ reactions. In the case of the SPME/GC-TOFMS system, a set of experiments using field ionization was carried out in order to help establish the identification of reaction products.

Time-concentration profiles of 3,3DM1ButOH, 3,3dimethylbutanal, and those reaction products positively identified by FTIR analysis were made to test whether the profiles correspond to primary or secondary reaction products. An example of the reactions with $\mathrm{Cl}$ atoms in the absence/presence of $\mathrm{NO}_{x}$ is presented in Fig. 6, showing that in the absence of $\mathrm{NO}_{x}$ the profiles of acetone and formaldehyde have two trends. This indicates that these compounds are formed as primary and secondary products. This profile is clearly observed for nitrated compounds in the reaction with $\mathrm{Cl}$ atoms in the presence of $\mathrm{NO}_{x}$ (Fig. 6b).

A commercial sample of 3,3-dimethylbutanal was used to estimate the molecular yields in both experimental systems. These are shown in Table 4. The yields of acetone and formaldehyde were calculated using a FTIR reference spectrum of a commercial sample and a FTIR reference spectra from the Eurochamp database (https://data.eurochamp.org/ data-access/spectra/, last access: 3 June 2019), respectively. A FTIR reference spectrum of 2-methylpropanal (from this same database) was used to estimate the molecular yield of 2,2-dimethylpropanal.

The amounts of 3,3-dimethylbutanal formed were corrected by their reactions with $\mathrm{Cl}$ atoms and with $\mathrm{OH}$ and $\mathrm{NO}_{3}$ radicals using the rate coefficients available in the literature or for reactions of structurally similar compounds (see the footnote for Table 4). Estimated yields of formaldehyde, acetone, 2,2-dimethylpropanal, and nitrated compounds are summarized in Table 6 along with an average yield of 3,3dimethylbutanal. The higher yield of nitrated compounds in the reaction of 3,3DM1ButOH with the nitrate radical could indicate an extra formation of nitrated compounds from secondary reactions (see Fig. S8). Total carbon yields of $60 \%$, 
Table 4. Experimental conditions and molecular yields of 3,3-dimethylbutanal for the reaction of 3,3DM1ButOH with atmospheric oxidants.

\begin{tabular}{|c|c|c|c|c|c|c|c|c|c|}
\hline SA & Oxidant & Exp & $\begin{array}{r}\text { [SA] } \\
(\mathrm{ppm})\end{array}$ & $\begin{array}{r}\text { [Precursor] } \\
(\mathrm{ppm})\end{array}$ & $\begin{array}{r}{[\mathrm{NO}]} \\
(\mathrm{ppm})\end{array}$ & $\begin{array}{r}\text { Carbonyl } \\
\text { compound } \\
\text { yield }^{\mathrm{f}} \\
(\%)\end{array}$ & Technique & $\begin{array}{r}\text { Averageg } \\
(\%)\end{array}$ & $\begin{array}{l}\text { SAR } \\
\text { yield } \\
(\%)\end{array}$ \\
\hline \multirow[t]{16}{*}{ 3,3DM1ButOH } & \multirow[t]{4}{*}{$\mathrm{Cl}^{\mathrm{a}}$} & 1 & 11 & 24 & - & $40.3 \pm 0.2$ & FTIR & \multirow[t]{4}{*}{$39.4 \pm 15.0$} & \multirow[t]{8}{*}{40} \\
\hline & & & & & & $41.8 \pm 4.6$ & SPME/GC-TOFMS $^{\mathrm{d}}$ & & \\
\hline & & 2 & 2.6 & 8 & - & $19.6 \pm 0.5$ & SPME/GC-TOFMS & & \\
\hline & & 3 & 6 & 25 & - & $55.9 \pm 1.7$ & FTIR & & \\
\hline & \multirow[t]{4}{*}{$\mathrm{Cl}^{\mathrm{a}}+\mathrm{NO}$} & 1 & 10 & 21 & 21 & $61.6 \pm 3.4$ & FTIR & \multirow[t]{4}{*}{$43.3 \pm 17.7$} & \\
\hline & & & & & & $34.7 \pm 4.4$ & SPME/GC-TOFMS ${ }^{\mathrm{d}}$ & & \\
\hline & & 2 & 4 & 9 & 8 & $23.0 \pm 4.2$ & SPME/GC-TOFMS ${ }^{\mathrm{e}}$ & & \\
\hline & & 3 & 10 & 25 & 25 & $48.8 \pm 0.6$ & FTIR & & \\
\hline & \multirow[t]{5}{*}{$\mathrm{OH}^{\mathrm{b}}$} & 1 & 10 & 60 & 36 & $82.1 \pm 4.2$ & FTIR & \multirow[t]{5}{*}{$62.2 \pm 15.0$} & \multirow[t]{5}{*}{66} \\
\hline & & & & & & $40.8 \pm 2.7$ & SPME/GC-TOFMS ${ }^{\mathrm{d}}$ & & \\
\hline & & 2 & 7 & 35 & 57 & $67.4 \pm 1.4$ & FTIR & & \\
\hline & & 3 & 11 & 28 & 55 & $61.9 \pm 0.9$ & FTIR & & \\
\hline & & 4 & 11 & 29 & 30 & $59.1 \pm 3.8$ & FTIR & & \\
\hline & \multirow[t]{3}{*}{$\mathrm{NO}_{3}^{\mathrm{c}}$} & 1 & 11 & 36 & - & $29.2 \pm 0.5$ & FTIR & \multirow[t]{3}{*}{$36.2 \pm 14.6$} & \multirow[t]{3}{*}{86} \\
\hline & & & & & & $53.9^{\mathrm{h}}$ & SPME/GC-TOFMS ${ }^{\mathrm{d}}$ & & \\
\hline & & 2 & 11 & 32 & - & $26.5 \pm 1.6$ & FTIR & & \\
\hline
\end{tabular}

a Rate coefficient of $k=1.7 \times 10^{-10}$ (in $\mathrm{cm}^{3}$ molecule ${ }^{-1} \mathrm{~s}^{-1}$ ) used to correct the concentration of 3,3-dimethylbutanal by loss with the reaction of $\mathrm{Cl}$ atoms (data of isobutyraldehyde and $\mathrm{Cl}$ atoms from Thevenet et al., 2000). Photolysis rate coefficient estimated for 3,3-dimethylbutanal under our experimental conditions, $k_{\mathrm{p}}=1 \times 10^{-4} \mathrm{~s}^{-1}$. ${ }^{\mathrm{b}}$ Rate coefficient of $k=2.73 \times 10^{-11}$ (in cm ${ }^{3}$ molecule ${ }^{-1} \mathrm{~s}^{-1}$ ) used to correct the concentration of 3,3-dimethylbutanal by loss with the reaction of OH radical (Aschmann et al., 2010). Photolysis rate coefficient estimated for 3,3-dimethylbutanal under our experimental conditions, $k_{\mathrm{p}}=1 \times 10^{-4} \mathrm{~s}^{-1}$. ${ }^{\mathrm{c}}$ Rate coefficient of $k=1.27 \times 10^{-14}$ (in cm ${ }^{3}$ molecule ${ }^{-1} \mathrm{~s}^{-1}$ ) used to correct the concentration of 3,3-dimethylbutanal by loss with the reaction of $\mathrm{NO}_{3}$ radical (D'Anna et al., 2001).

${ }^{\mathrm{d}}$ Experiment using a $50 \mathrm{~L}$ FTIR gas cell. ${ }^{\mathrm{e}}$ Experiment using a $150 \mathrm{~L}$ Teflon gas bag. ${ }^{\mathrm{f}}$ Indicated errors are the errors associated with the slope of plots obtained in the least squares analysis. ${ }^{\mathrm{g}}$ Standard deviations $1 \sigma .{ }^{\mathrm{h}}$ Yield estimated using only experimental data.

$81 \%$, and $36 \%$ have been justified for $\mathrm{Cl}, \mathrm{OH}$, and $\mathrm{NO}_{3}$ reactions, respectively. It must be noted that there are reaction products that could not be quantified as dihydroxy or hydroxycarbonyl compounds in the reactions with $\mathrm{Cl}$ atoms in the absence of $\mathrm{NO}_{x}$ and primary nitrated compounds in the reactions with $\mathrm{Cl}$ atoms in the presence of $\mathrm{NO}_{x}$ and with the $\mathrm{NO}_{3}$ radical.

This work is the first study of the products of the reaction of 3,3DM1ButOH with atmospheric oxidants; therefore, there is no other study with which to compare the results. Figure 7 shows the reaction mechanism proposed based on existing studies of saturated alcohols' reactions with $\mathrm{Cl}$ atoms and the $\mathrm{OH}$ radical in the literature (Cavalli et al., 2002; Hurley et al., 2009; McGillen et al., 2013; Welz et al., 2013) and considering the reaction products identified in our work. Table S2 shows a summary of the reaction products, either observed or tentatively identified, proposed in this mechanism of the reaction of 3,3DM1ButOH with the atmospheric oxidants.

As can be seen from Table 4, the estimated molecular yields of 3,3-dimethylbutanal (formed by $\mathrm{H}$ atom abstraction at the $\alpha$-position of 3,3DM1BuOH) are very similar to those predicted by the SAR method for the $\mathrm{Cl}$ and $\mathrm{OH}$ reactions. In the case of the $\mathrm{NO}_{3}$ radical, a large difference between yields was observed (36\% estimated in this work and $86 \%$ predicted by SAR). This discrepancy could be explained by the fact that the SAR method applied to the $\mathrm{NO}_{3}$ radical reaction with primary alcohols (Kerdouci et al., 2010, 2014) underestimates the attack of $\mathrm{NO}_{3}$ at the $\beta$-position, as it does not consider the possible activating effect of the $-\mathrm{CH}_{2} \mathrm{OH}$ group (see Sect. S2). This could also explain the large difference observed between the estimated and measured rate coefficients of the reaction of 3,3DM1ButOH with $\mathrm{NO}_{3}$, as shown in Table 2. Moreover, the volume of the reactor could also have an influence on formation of 3,3-dimethylbutanal.

According to the molecular yields of the products quantified and/or observed in the SPME/GC-TOFMS chromatograms, it can be concluded that route I (attack at the $\alpha$-position) seems to be the main reaction route for the $\mathrm{OH}$ radical reaction. For $\mathrm{Cl}$ atoms, the three routes can occur to a significant extent. The major molecular yields of formaldehyde and acetone (route III) in the reactions with $\mathrm{Cl}$ atoms in the presence of $\mathrm{NO}_{x}$ versus those of in the absence of $\mathrm{NO}_{x}$ could indicate that the self reactions of peroxy radicals $\left(\mathrm{RO}_{2} \bullet\right)$ via the molecular pathway are more favored than reactions via the radical pathway in the absence of $\mathrm{NO}_{x}$. For the $\mathrm{NO}_{3}$ radical, routes I and II (attack at the $\beta$-position) with 


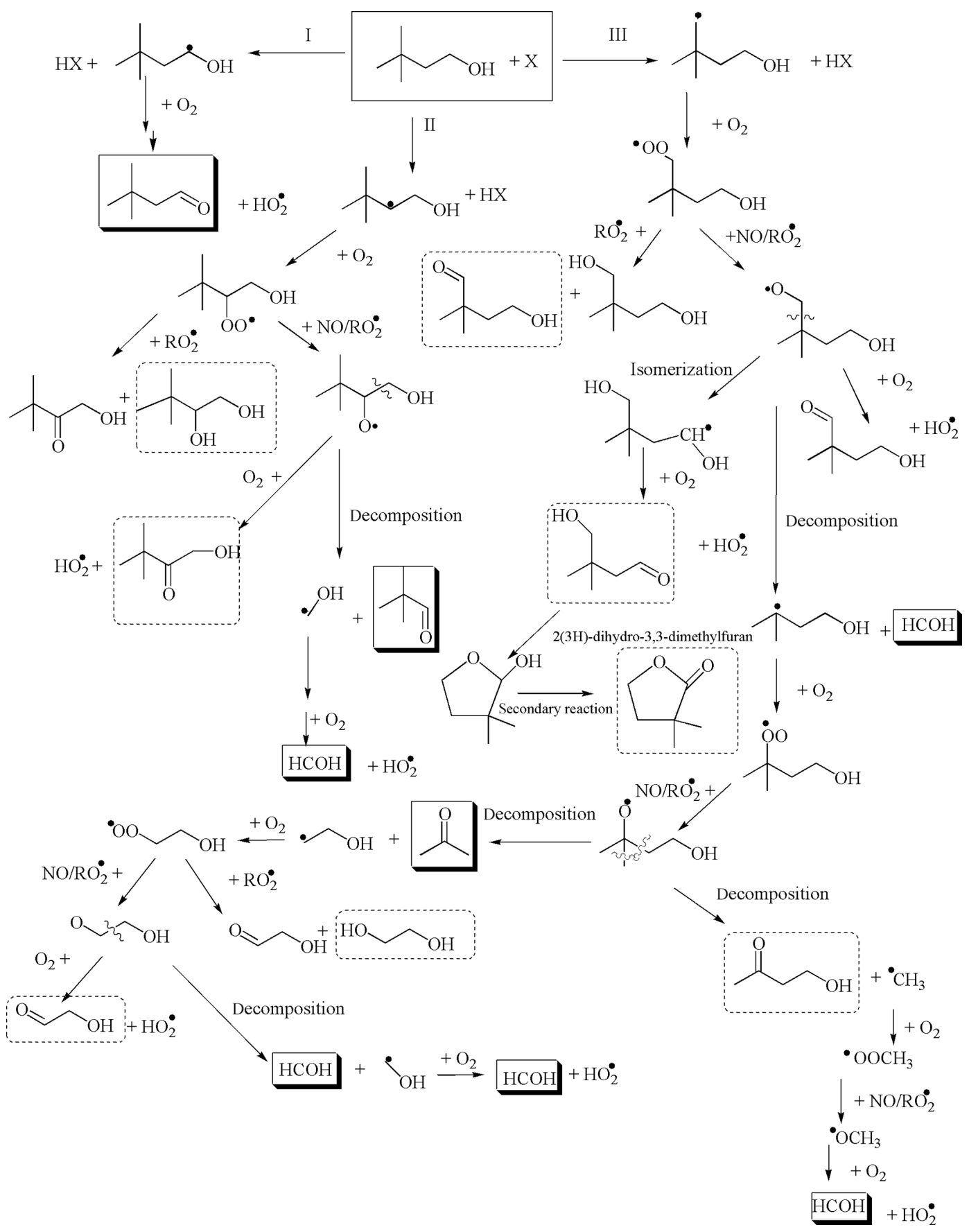

Figure 7. Reaction mechanism for the degradation of 3,3DM1ButOH with $\mathrm{X}$ (the $\mathrm{Cl}$ atom and the $\mathrm{OH}$ and $\mathrm{NO}_{3}$ radicals). The mechanism for the formation of carbonyl compounds. Compounds marked with a solid line are positively identified. Compounds marked with a dotted line are not positively identified.

the formation of nitrated compounds seem to be the major routes.

\subsubsection{3,3DM2ButOH}

Analysis of the FTIR spectra obtained for the reactions of 3,3DM2ButOH with $\mathrm{Cl}$ atoms in the presence/absence of
$\mathrm{NO}_{x}$, the $\mathrm{OH}$ radical, and the $\mathrm{NO}_{3}$ radical shows the formation of 3,3-dimethyl-2-butanone as a main product (see Fig. S9). Other compounds, such as formaldehyde, acetone, 2,2-dimethylpropanal, and peroxyacetyl nitrate (PAN), were also observed. The residual FTIR spectra after the subtraction of all known IR bands again shows the presence of carbonyl compounds (IR absorption in the range from 1820 to 


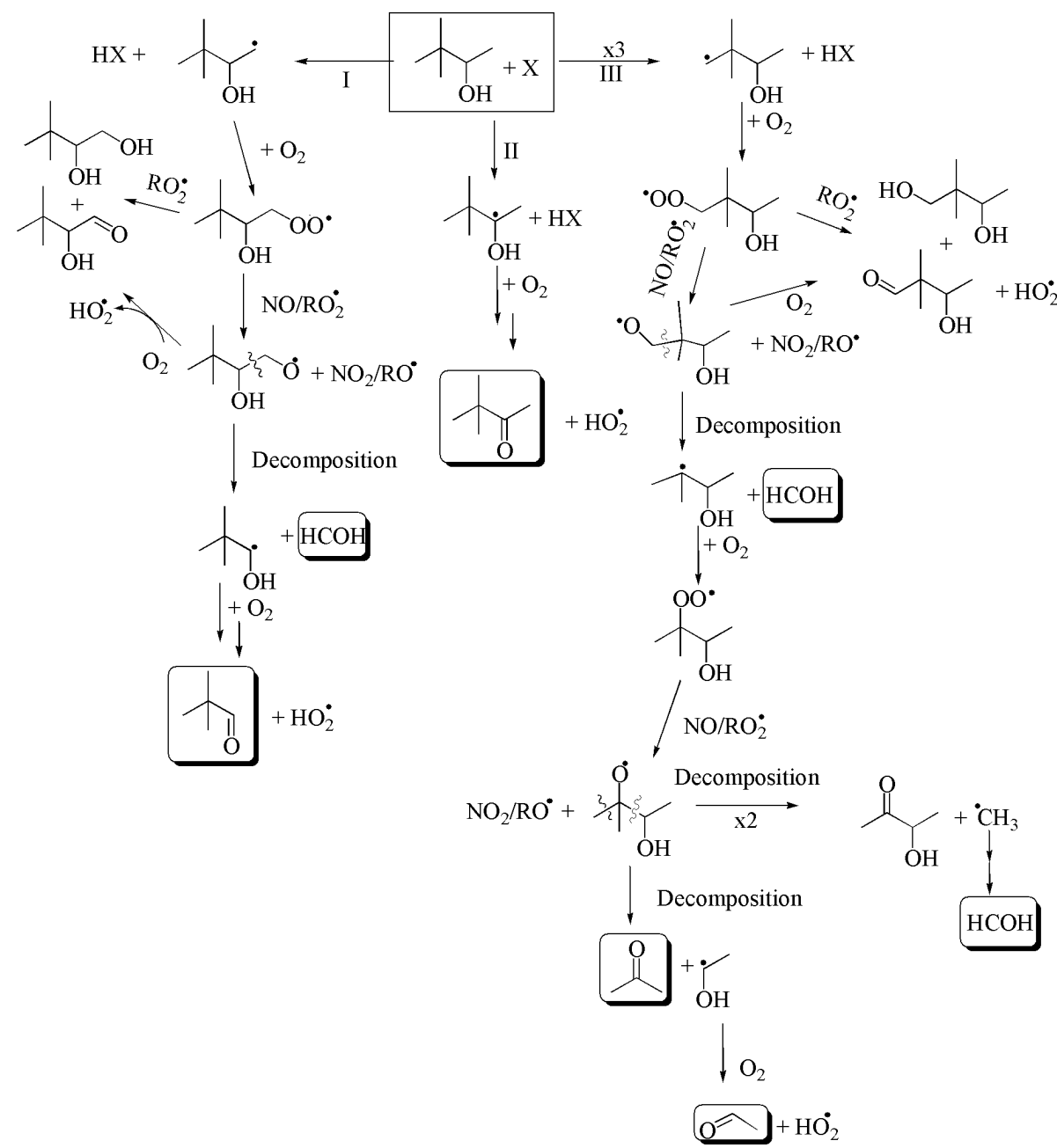

Figure 8. Reaction mechanism for the degradation of 3,3DM2ButOH with $\mathrm{X}$ (the $\mathrm{Cl}$ atom and the $\mathrm{OH}$ and $\mathrm{NO}_{3}$ radicals). The mechanism for the formation of carbonyl compounds. Compounds marked with a solid line are positively identified. Compounds marked with a dotted line are not positively identified.

$\left.1700 \mathrm{~cm}^{-1}\right)$, hydroxy compounds $\left(1060-1040 \mathrm{~cm}^{-1}\right)$ in the reaction with $\mathrm{Cl}$ atoms in the absence of $\mathrm{NO}_{x}$, and also nitrated compounds $\left(\mathrm{RONO}_{2} ; 1650,1305-1260,890 \mathrm{~cm}^{-1}\right)$ in the reaction with $\mathrm{Cl}$ in the presence of $\mathrm{NO}_{x}$ and the $\mathrm{NO}_{3}$ radical (Fig. S9c). The presence of an IR absorption band around $1800 \mathrm{~cm}^{-1}$ for the reaction with $\mathrm{Cl}$ atoms at long reaction times in the residual FTIR spectra could be due to the formation of $\mathrm{Cl}$ compounds by reaction of 3,3-dimethyl2-butanone with $\mathrm{Cl}_{2}$ (Ren et al., 2018) or the formation of cyclic compounds such as hydrofurans. The SPME/GCTOFMS chromatograms and MS spectra (Figs. S10 and S11) confirm the presence of other reaction products (apart from 3,3-dimethyl-2-butanone) in the case of $\mathrm{Cl}$ (in the absence/presence of $\mathrm{NO}_{x}$ ) and $\mathrm{NO}_{3}$ reactions. Only one significant peak is observed in chromatograms of the $\mathrm{OH}$ reactions.

The estimated molecular yields of 3,3-dimethyl-2butanone for all individual experiments are given in Table 5, where the measured concentrations have been cor- rected for secondary reactions. Acetone, formaldehyde, 2,2dimethylpropanal, nitrated compounds, and acetaldehyde were also quantified. Plots of concentration versus time for formaldehyde, acetone (Fig. S12a), and nitrated compounds in the reactions of $\mathrm{Cl}$ in the presence of $\mathrm{NO}_{x}$ (Fig. S12b) show profiles with two trends. This type of profile indicates that formaldehyde and acetone could also be formed by the degradation of 3,3-dimethyl-2-butanone (Fig. S13). Table 6 summarizes the molecular yields of all quantified products.

Total carbon yields of $\sim 60 \% / 100 \%, 90 \%$, and $60 \%$ have been reported for $\mathrm{Cl}$ (in the absence and presence of $\mathrm{NO}_{x}$ ), $\mathrm{OH}$, and $\mathrm{NO}_{3}$ reactions, respectively (see Table 6). It is important to note that in the case of the reaction of $\mathrm{Cl}$ atoms in the absence of $\mathrm{NO}_{x}$, where the total carbon yield was lower than $100 \%$, there were many reaction products that could not be quantified, such as dihydroxy and/or hydroxycarbonyl compounds. In the reaction with the $\mathrm{NO}_{3}$ radical, due to our 
Table 5. Experimental conditions and molecular yields of 3,3-dimethyl-2-butanone for the reaction of 3,3DM2ButOH with atmospheric oxidants.

\begin{tabular}{|c|c|c|c|c|c|c|c|c|c|}
\hline SA & Oxidant & Exp & $\begin{array}{r}{[\mathrm{SA}]} \\
(\mathrm{ppm})\end{array}$ & $\begin{array}{r}\text { [Precursor] } \\
(\mathrm{ppm})\end{array}$ & $\begin{array}{r}{[\mathrm{NO}]} \\
(\mathrm{ppm})\end{array}$ & $\begin{array}{r}\text { Carbonyl } \\
\text { compound } \\
\text { yield }^{f}(\%)\end{array}$ & Technique & $\begin{array}{r}\text { Average } e^{g} \\
(\%)\end{array}$ & $\begin{array}{r}\text { SAR } \\
\text { yield } \\
(\%)\end{array}$ \\
\hline \multirow[t]{14}{*}{ 3,3DM2ButOH } & \multirow[t]{3}{*}{$\mathrm{Cl}^{\mathrm{a}}$} & 1 & 14 & 31 & - & $42.8 \pm 0.7$ & FTIR & $43.2 \pm 1.8$ & 40 \\
\hline & & & & & & $45.2 \pm 1.1$ & SPME/GC-TOFMS ${ }^{\mathrm{d}}$ & & \\
\hline & & 2 & 2.3 & 8 & - & $41.7 \pm 3.2$ & SPME/GC-TOFMS ${ }^{\mathrm{e}}$ & & \\
\hline & \multirow[t]{4}{*}{$\mathrm{Cl}^{\mathrm{a}}+\mathrm{NO}$} & 1 & 14 & 28 & 20 & $36.7 \pm 5.0$ & FTIR & $44.2 \pm 7.4$ & \\
\hline & & & & & & $49.6 \pm 4.5$ & SPME/GC-TOFMS $^{\mathrm{d}}$ & & \\
\hline & & 2 & 3 & 7 & 6 & $39.0 \pm 6.1$ & SPME/GC-TOFMS ${ }^{\mathrm{e}}$ & & \\
\hline & & 3 & 8 & 28 & 27 & $51.5 \pm 3.9$ & FTIR & & \\
\hline & \multirow[t]{4}{*}{$\mathrm{OH}^{\mathrm{b}}$} & 1 & 8 & 55 & 42 & $82.8 \pm 3.1$ & FTIR & $80.7 \pm 6.5$ & 91 \\
\hline & & & & & & $71.2 \pm 2.6$ & SPME/GC-TOFMS ${ }^{\mathrm{d}}$ & & \\
\hline & & 2 & 5 & 66 & 36 & $85.4 \pm 5.8$ & FTIR & & \\
\hline & & 3 & 11 & 28 & 29 & $83.6 \pm 3.0$ & FTIR & & \\
\hline & \multirow[t]{3}{*}{$\mathrm{NO}_{3}^{\mathrm{c}}$} & 1 & 12 & 30 & - & $66.7 \pm 2.05$ & FTIR & \multirow[t]{3}{*}{$58.0 \pm 10.9$} & \multirow[t]{3}{*}{99} \\
\hline & & & & & & $45.9 \pm 1.6$ & SPME/GC-TOFMS $^{\mathrm{d}}$ & & \\
\hline & & 2 & 9 & 30 & - & $61.5 \pm 1.4$ & FTIR & & \\
\hline
\end{tabular}

a Rate coefficient of $k=4.8 \times 10^{-11}$ (in $\mathrm{cm}^{3}$ molecule ${ }^{-1} \mathrm{~s}^{-1}$ ) used to correct the concentration of 3,3-dimethyl-2-butanone by loss with the reaction of Cl atoms (Farrugia et al., 2015). Photolysis rate coefficient estimated for 3,3-dimethyl-2-butanone under our experimental conditions, $k_{\mathrm{p}}=7 \times 10^{-5} \mathrm{~s}-1$. ${ }^{\mathrm{b}}$ Rate coefficient of $k=1.21 \times 10^{-12}$ (in $\mathrm{cm}^{3}$ molecule ${ }^{-1} \mathrm{~s}^{-1}$ ) used to correct the concentration of 3,3-dimethyl-2-butanone by loss with the reaction of the OH radical (Wallington and Kurylo, 1987). Photolysis rate coefficient estimated for 3,3-dimethyl-2-butanone under our experimental conditions, $k_{\mathrm{p}}=7 \times 10^{-5} \mathrm{~s}^{-1}$. ${ }^{\mathrm{c}}$ Not corrected. ${ }^{\mathrm{d}}$ Experiment using a 50 L FTIR gas cell.

${ }^{\mathrm{e}}$ Experiment using a $150 \mathrm{~L}$ Teflon gas bag. ${ }^{\mathrm{f}}$ Indicated errors are the errors associated with the slope of plots obtained in the least squares analysis. ${ }^{\mathrm{g}}$ Standard deviations $1 \sigma$.

experimental conditions, a significant number of primary nitrated compounds were expected to be formed (Fig. S9c).

A mechanism of hydrogen atom abstraction at different positions on the carbon chain has been proposed for the reaction of 3,3DM2ButOH with $\mathrm{Cl}, \mathrm{OH}$, and $\mathrm{NO}_{3}$. The mechanism is shown in Fig. 8. Table S3 shows a summary of the reaction products, either observed or tentatively identified, proposed by this mechanism of the reactions of 3,3DM2ButOH with the atmospheric oxidants.

Molecular yields of 3,3-dimethyl-2-butanone obtained in this work imply percentages of attack of the oxidant at the $\alpha$-position (route II) of $43 \% / 44 \%$ in the case of $\mathrm{Cl}$ atom (in the absence/presence of $\mathrm{NO}_{x}$ ), $81 \%$ for the $\mathrm{OH}$ radical, and $58 \%$ for the $\mathrm{NO}_{3}$ radical. Percentages are very similar to those predicted by $\mathrm{SAR}$ methods except for the $\mathrm{NO}_{3}$ radical (see Table 5). The high $\mathrm{NO}_{2}$ concentration present in the reactions with the $\mathrm{NO}_{3}$ radical would greatly favor the formation of nitrated compounds over 3,3-dimethyl-2-butanone. It could also justify the low estimated molecular yield for 3,3dimethyl-2-butanone.

The main reaction products observed in the reaction with $\mathrm{Cl}$ atoms in the presence of $\mathrm{NO}_{x}$ (3,3-dimethyl-2-butanone, formaldehyde, 2,2-dimethylpropanal, acetone, and acetaldehyde) confirm the attack of $\mathrm{Cl}$ atoms at other sites apart from the $\alpha$-position. Based on the estimated molecular yield of acetone, attack at the $\delta$-position with the abstraction of the hydrogen atom from methyl groups (route III) could be $\sim 58 \%$, and based on the estimated molecular yield of 2,2dimethylpropanal, the attack at the $\beta$-position (route I) could account for $10 \%$. These data agree with the SAR predictions for $\mathrm{Cl}$ atom reactions. Moreover, the major molecular yields of acetone, formaldehyde, and acetaldehyde (route III) in the reaction with $\mathrm{Cl}$ atoms in the presence of $\mathrm{NO}_{x}$ rather than in its absence could indicate that the self-reactions of peroxy radicals via the molecular pathway is negligible in the presence of $\mathrm{NO}_{x}$. The lower yield of acetaldehyde estimated $(17 \%)$ versus $58 \%$ of its coproduct (acetone) is due to its fast degradation by reaction with $\mathrm{Cl}$ atoms with the formation PAN, as observed in the FTIR experiments (see Fig. S9b).

\section{Atmospheric implications}

Pollutants in the atmosphere can create serious environmental problems, such photochemical smog, acid rain, and degradation of the ozone layer (Finlayson-Pitts and Pitts, 2000). Therefore, it is important to evaluate the parameters that help us to understand the impact of the presence of these compounds in the atmosphere. These parameters are the time that such compounds remain in the atmosphere, their global warming potential (GWP), and their mechanisms of degradation that allow us to estimate the atmospheric effect of the products formed.

The first important parameter with respect to the environmental impact of oxygenated volatile organic compounds in 
Table 6. Summary of molecular yields $(\%)$ of reaction products identified in the reaction of SAs with atmospheric oxidants and the total carbon balance $(\%)$.

\begin{tabular}{|c|c|c|c|c|}
\hline \multicolumn{5}{|l|}{ 4MCHexOH } \\
\hline Products & $\mathrm{Cl}$ & $\mathrm{Cl}+\mathrm{NO}$ & $\mathrm{OH}$ & $\mathrm{NO}_{3}$ \\
\hline (E)-4-Methylcyclohexanone ${ }^{1}$ & $25.2 \pm 1.9$ & $29.5 \pm 0.7$ & $40.2 \pm 5.4$ & $58.0 \pm 23.5$ \\
\hline $\mathrm{HCOH}^{2}$ & 9 & - & - & - \\
\hline Nitrated compounds & - & 20 & 10 & 60 \\
\hline Total carbon ${ }^{3}$ & 26 & 50 & 50 & $\sim 100$ \\
\hline \multicolumn{5}{|l|}{ 3,3DM1ButOH } \\
\hline Products & $\mathrm{Cl}$ & $\mathrm{Cl}+\mathrm{NO}$ & $\mathrm{OH}$ & $\mathrm{NO}_{3}$ \\
\hline 3,3-Dimethylbutanal ${ }^{1}$ & $39.4 \pm 15.0$ & $43.3 \pm 17.7$ & $62.2 \pm 15.0$ & $36.2 \pm 14.6$ \\
\hline $\mathrm{HCOH}^{2}$ & 10 & 22 & - & - \\
\hline 2,2-Dimethylpropanal ${ }^{2}$ & 22 & 8 & 23 & - \\
\hline Acetone $^{2}$ & 5 & 17 & - & - \\
\hline Nitrated compounds & - & $40^{5}$ & $35^{6}$ & $200^{7}$ \\
\hline Total carbon ${ }^{3,4}$ & 61 & 62 & 81 & 36 \\
\hline \multicolumn{5}{|l|}{ 3,3DM2ButOH } \\
\hline Products & $\mathrm{Cl}$ & $\mathrm{Cl}+\mathrm{NO}$ & $\mathrm{OH}$ & $\mathrm{NO}_{3}$ \\
\hline 3,3-Dimethyl-2-butanone ${ }^{1}$ & $43.2 \pm 1.8$ & $44.2 \pm 7.4$ & $80.7 \pm 6.5$ & $58.0 \pm 10.9$ \\
\hline $\mathrm{HCOH}^{2}$ & 10 & 64 & - & - \\
\hline 2,2-Dimethylpropanal ${ }^{2}$ & 14 & 10 & 14 & - \\
\hline Acetone $^{2}$ & 3 & 58 & - & _ \\
\hline Acetaldehyde $^{2}$ & - & 17 & - & - \\
\hline Nitrated compounds & - & 30 & 20 & 120 \\
\hline Total carbon 3,4 & $\sim 60$ & 98 & 93 & 58 \\
\hline
\end{tabular}

${ }^{1}$ Average Tables $3-5 .{ }^{2}$ Molecular yield obtained in earlier step of the reaction. ${ }^{3}$ Total carbon (\%)

$=\sum_{1}^{i}\left(\frac{\text { no. of carbon of product }}{\text { no. of carbon of SA }} \times\right.$ molar yield $\left._{i}(\%)\right) \cdot{ }^{4}$ Nitrate compounds were not accounted for. ${ }^{5}$ From analysis of experiment number 3 for the reaction of $\mathrm{Cl}$ in the presence of $\mathrm{NO}_{x} \cdot{ }^{6}$ From average of experiments number 2, 3, and 4 for the reaction with $\mathrm{OH} .{ }^{7}$ From analysis of experiments number 1 and 2 for reaction with $\mathrm{NO}_{3}$.

Table 7. Lifetimes of 4MCHexOH, 3,3DM1ButOH, and 3,3DM2ButOH.

\begin{tabular}{lrrrrrr}
\hline & $\tau_{\mathrm{OH}}(\mathrm{d})$ & $\tau_{\mathrm{Cl}}{ }^{\mathrm{a}}(\mathrm{d})$ & $\tau_{\mathrm{Cl}}{ }^{\mathrm{b}}(\mathrm{d})$ & $\tau_{\mathrm{NO} 3}(\mathrm{~d})$ & $\tau_{\text {wet }}($ years $)$ & $\tau_{\text {global }}^{\mathrm{a}}(\mathrm{d})$ \\
\hline 4MCHexOH & 0.62 & 31.28 & 0.24 & 8.61 & $\sim 2.1$ & 0.58 \\
3,3DM1ButOH & 2.17 & 43.03 & 0.33 & $13^{\mathrm{c}}$ & $\sim 15.8$ & 1.78 \\
3,3DM2ButOH & 1.10 & 95.65 & 0.74 & $6.73^{\mathrm{c}}$ & 11.3 & 0.94 \\
\hline
\end{tabular}

a Determined using the $24 \mathrm{~h}$ average of chlorine atoms. ${ }^{\mathrm{b}}$ Determined using the peak concentration of chlorine atoms.

${ }^{c}$ Determined using the rate coefficient obtained by Moreno et al. (2014).

the atmosphere is the global lifetime, $\tau_{\text {global }}$, which considers all of the degradation processes that could affect these compounds in the troposphere. This parameter can be obtained from the sum of the individual sink processes, such as reactions initiated by $\mathrm{OH}$ and $\mathrm{NO}_{3}$ radicals, $\mathrm{Cl}$ atoms, and $\mathrm{O}_{3}$ molecules as well as photolysis and dry and wet deposition,
Eq. (4):

$$
\begin{aligned}
\tau_{\text {global }} & =\left[\frac{1}{\tau_{\mathrm{OH}}}+\frac{1}{\tau_{\mathrm{Cl}}}+\frac{1}{\tau_{\mathrm{NO}_{3}}}+\frac{1}{\tau_{\mathrm{O}_{3}}}+\frac{1}{\tau_{\text {photolysis }}}\right. \\
& \left.+\frac{1}{\tau_{\text {other processes }}}\right]^{-1} .
\end{aligned}
$$

The tropospheric lifetimes $(\tau)$ of $4 \mathrm{MCHexOH}$, $3,3 \mathrm{DM} 1 \mathrm{ButOH}$, and 3,3DM2ButOH for each process 
have been estimated by considering Eqs. (4) and (5):

$\tau=\frac{1}{k_{\mathrm{Ox}}[\mathrm{Ox}]}$,

where $k_{\mathrm{OX}}$ and $[\mathrm{Ox}]$ are the rate coefficients obtained in this work for each oxidant and the typical atmospheric concentrations of the oxidants $\mathrm{Cl}, \mathrm{OH}$, and $\mathrm{NO}_{3}$, respectively. The concentrations employed were $1 \times 10^{3}$ atoms cm$^{-3}$ for the $24 \mathrm{~h}$ average for $\mathrm{Cl}$ (Platt and Janssen, 1995), $1 \times$ $10^{6}$ radicals $\mathrm{cm}^{-3}$ for the $12 \mathrm{~h}$ average daytime concentra-

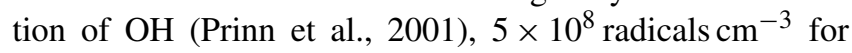
the $12 \mathrm{~h}$ average daytime concentration of $\mathrm{NO}_{3}$ (Atkinson, 2000), and a peak concentration of $1.3 \times 10^{5}$ atoms cm$~^{-3}$ for $\mathrm{Cl}$ in the coastal marine boundary layer at dawn (Spicer et al., 1998). Reactions with $\mathrm{O}_{3}$ and photolysis are negligible loss processes for this type of compound (Mellouki et al., 2015). Other processes are referred to as dry and wet deposition. To estimate the lifetime associated with wet deposition, Eq. (6) proposed by (Chen et al., 2003) was used:

$\tau_{\mathrm{wet}}=\frac{H_{\mathrm{atm}}}{v_{\mathrm{pm}} R T k_{\mathrm{H}}}$,

where $k_{\mathrm{H}}$ is the Henry's law constant; $H_{\mathrm{atm}}$ is the height of the troposphere, taking a value of $630 \mathrm{~m} ; v_{\mathrm{pm}}$ is the average precipitation rate for Ciudad Real (Spain) (402 $\mathrm{mm} \mathrm{yr}^{-1}$ ) (http://www.aemet.es, last access: 10 May 2019); $R$ is the gas constant; and $T$ is the temperature, considered to be constant and equal to $298 \mathrm{~K}$. In the literature, there are only data of Henry's constant for 3,3DM2ButOH $(5.6 \times$ $10^{-1} \mathrm{~mol} \mathrm{~m}^{-3} \mathrm{~Pa}^{-1}$; Sander, 2015). To compare the available data for similar compounds, approximated values of $K_{\mathrm{H}}$ of 3 and $0.4 \mathrm{~mol} \mathrm{~m}^{-3} \mathrm{~Pa}^{-1}$ have been used for $4 \mathrm{MCHexOH}$ and 3,3DM1ButOH, respectively.

The calculated lifetimes of the three alcohols studied in this work are shown in Table 7. It can be seen that the dominant tropospheric loss process for the three alcohols is clearly their reaction with $\mathrm{OH}$ radicals followed by their reaction with $\mathrm{NO}_{3}$ radicals at night. However, in places where there is a peak concentration of $\mathrm{Cl}$ atoms (coastal areas), the reaction of these alcohols with $\mathrm{Cl}$ atoms may compete with the reaction with $\mathrm{OH}$ radicals as their main degradation process.

The global lifetime of the three alcohols is of the order of $\sim 1-2 \mathrm{~d}$, indicating that these compounds will probably be degraded near their sources. These global lifetimes also indicate that SAs do not make a significant contribution to the radiative forcing of climate change (Mellouki et al., 2015), which is supported by the estimation of their GWP values. For a time horizon of 20 years, the estimated values are $8.33 \times 10^{-4}, 1.78 \times 10^{-2}$, and $5.80 \times 10^{-3}$ for $4 \mathrm{MCHexOH}$, 3,3DM1ButOH, and 3,3DM2ButOH, respectively, which are very low. Therefore, these compounds will only have an important impact in the troposphere at a the local or regional level.

Their degradation products (mostly carbonyl-containing compounds and nitro-compounds in polluted areas) must be considered. Thus, the nitrated compounds generated can act as $\mathrm{NO}_{x}$ reservoir species, especially during the night (Altshuller, 1993), and could have an influence at the global scale. Moreover, as 4MCHexOH, 3,3DM1ButOH, and 3,3DM2ButOH react quickly with $\mathrm{Cl}$ atoms and $\mathrm{OH}$ radicals, their contribution to the formation of photochemical smog might be important. For that reason, the contribution of these three alcohols to the formation of smog was estimated by obtaining the average ozone production during $99 \%$ of their reactions with the $\mathrm{OH}$ radical, using the equation indicated by Dash and Rajakumar (2013). The values obtained were 3.24, 0.90, and $1.69 \mathrm{ppm}$ for 4MCHexOH, 3,3DM1ButOH, and 3,3DM2ButOH, respectively. These values suggest that these compounds may be potential generators of tropospheric ozone and could contribute significantly to the formation of photochemical smog depending on their concentrations in the atmosphere.

\section{Conclusions}

The main conclusions obtained from the present study are as follows:

- The kinetic and product study support that (1) the atmospheric degradation mechanism for SAs, and possibly for other unstudied saturated alcohols, proceeds by the abstraction of a hydrogen atom bonded to a carbon rather than a hydrogen atom bonded to the oxygen atom of the alcohol group; and (2) the reaction mechanism in the $\mathrm{H}$ atom abstraction process depends on the oxidant. $\mathrm{Cl}$ atoms abstract any type of hydrogen $(\alpha, \beta, \delta)$ from SAs with a high percentage compared to the $\mathrm{OH}$ and the $\mathrm{NO}_{3}$ radicals. The $\mathrm{OH}$ and $\mathrm{NO}_{3}$ radicals mainly abstract the hydrogen atom at the $\alpha$-position if the saturated alcohols are secondary. For primary alcohols, the abstraction of a hydrogen atom at the $\beta$-position could also be important in the reaction with the $\mathrm{NO}_{3}$ radical. Therefore, more kinetic studies of the $\mathrm{NO}_{3}$ radical reaction with primary alcohols are necessary to quantify the effect of the $\mathrm{OH}$ group at the $\beta$-position $\left(-\mathrm{CH}_{2} \mathrm{OH}\right)$ and to update the SAR method developed by Kerdouci et al. (2010, 2014).

- Theoretical ab initio studies of the reactions of SAs with atmospheric oxidants should be performed in order to obtain more information about their reaction mechanisms in the $\mathrm{H}$ atom abstraction process.

- The atmospheric conditions determine the reaction mechanism and, therefore, the reaction products obtained in the degradation of SAs. Thus, in polluted environments with high concentrations of $\mathrm{NO}_{x}$, the peroxy radicals mainly react with $\mathrm{NO}$ to form the alkoxy radical instead of molecular compounds. Under these conditions, nitrated organic compounds $\left(\mathrm{RONO}_{2}\right)$ are formed 
as well as polyfunctional organic compounds. Moreover, when the concentration of $\mathrm{NO}_{2}$ is higher than that of $\mathrm{NO}$, ozone is formed. In a clean atmosphere, as in the case for the experiments with $\mathrm{Cl}$ atoms in the absence of $\mathrm{NO}_{x}$, the reaction products are different because peroxy radicals could react mainly via a self-reaction molecular pathway instead of via a self-reaction radical pathway with the formation of dihydroxy and hydroxycarbonyl compounds.

- The unquantified polyfunctional organic compounds could explain the low carbon balance obtained in the $\mathrm{Cl}$ or $\mathrm{NO}_{3}$ reactions. The carbon balance must be taken with caution as the calculated molecular yields have a high degree of uncertainty.

- Calculated lifetimes for saturated alcohols (of the order of $\sim 1 \mathrm{~d}$ ) imply that these compounds are pollutants at a local-regional scale, but it is also important to indicate that SAs are sources of stable nitrated compounds $\left(\mathrm{ROONO}_{2}\right)$, depending on environmental conditions, that can travel large distances from their sources and contribute to ozone formation in clean areas, such as forest or rural areas.

- The main products of the degradation of the SAs, aldehydes and ketones, develop a very important secondary chemistry with the formation of products of special relevance, such as the PAN observed in the degradation of 3,3-dimethyl-2-butanol. More experiments should be carried out using other detection techniques in order to evaluate the formation of secondary organic aerosol (SOA), because it is well known that polyfunctional organic compounds are important SOA precursors.

- From the environmental point of view, this work shows that the degradation of SAs is an important source of pollutants in the atmosphere of greater or lesser impact depending on the environmental conditions and the quantities of these alcohols present in the atmosphere. Therefore, the use of SAs as additives in the production of biofuels should be controlled, as poor handling could result in high concentrations of these alcohols in the atmosphere.

- The rate coefficients and reaction products reported in this work are the first available data for the abovementioned species; therefore, this work contributes to a better understanding of the atmospheric chemistry of oxygenated compounds, expands the kinetic and mechanistic database, and contributes to developing or to improving predictive models that help us to avoid or mitigate the effects of climate change or air quality deterioration. However, kinetic experiments in the tropospheric temperature range are necessary to obtain more information about the reaction mechanism and to extrapolate the rate coefficient data to other typical atmospheric conditions and, thus, be able to better establish the atmospheric impact of these alcohols.

Data availability. The underlying research data are available upon email request from the contact author of this work.

Supplement. The supplement related to this article is available online at: https://doi.org/10.5194/acp-20-699-2020-supplement.

Author contributions. SS and MP designed the experiments. CB was the leader of the research group, controlled the research, and obtained the financial support for the project leading to this publication. CI carried out the $4 \mathrm{MCHexOH}$ experiments, TA carried out the 3,3DM1ButOH and 3,3DM2ButOH kinetic experiments, and $\mathrm{AI}$ carried out the 3,3DM1ButOH and 3,3DM2ButOH product experiments. MP supervised the data analysis and prepared the paper with contributions from all co-authors.

Competing interests. The authors declare that they have no conflict of interest.

Acknowledgements. The authors, Inmaculada Colmenar, Araceli Tapia, and Inmaculada Aranda, wish to thank the Ministerio de Ciencia e Innovación and the Consejería de Ciencia y Tecnología de la Junta de Comunidades de Castilla-La Mancha for their financial support contracts.

Financial support. This research has been supported by the Ministerio de Ciencia e Innovación (project no. CGL2014-57087-R) and the Consejería de Ciencia y Tecnología de la Junta de Comunidades de Castilla-La Mancha (project no. SB-PLY/17/180501/000522).

Review statement. This paper was edited by James B. Burkholder and reviewed by two anonymous referees.

\section{References}

Allert, M., Rizk, S. S., Looger, L. L., Hellinga, H. W., and Wells, J.: A Computational Design of Receptors for an Organophosphate Surrogate of the Nerve Agent Soman, P. Natl. Acad. Sci. USA, 101, 7907-7912, https://doi.org/10.1073/pnas.0401309101, 2004.

Altshuller, A. P.: PANs in the Atmosphere, Air \& Waste, 43, 12211230, https://doi.org/10.1080/1073161X.1993.10467199, 1993.

Andersen, V. F., Wallington, T. J., and Nielsen, O. J.: Atmospheric Chemistry of i-Butanol, J. Phys. Chem. A, 114, 12462-12469, https://doi.org/10.1021/jp107950d, 2010.

AOPWIN: v1.92, @2000, U.S. Environmental Protection Agency, 2000. 
Aschmann, S. M. Arey, J., and Atkinson, R.: Kinetics and Products of the Reactions of OH Radicals with 4,4-Dimethyl-1-pentene and 3,3-Dimethylbutanal at 296 \pm 2 K, J. Phys. Chem. A, 114, 5810-5816, https://doi.org/10.1021/jp101893g, 2010.

Atkinson, R. Gas-phase tropospheric chemistry of organic compounds, J. Phys. Chem. Ref. Data, 2, 1-216, 1994.

Atkinson, R.: Atmospheric chemistry of $\mathrm{VOCs}$ and $\mathrm{NO}(\mathrm{x})$, Atmos. Environ., 34, 2063-2101, https://doi.org./10.1016/S13522310(99)00460-4, 2000.

Atkinson, R.: Kinetics of the gas-phase reactions of $\mathrm{OH}$ radicals with alkanes and cycloalkanes, Atmos. Chem. Phys., 3, 22332307, https://doi.org/10.5194/acp-3-2233-2003, 2003.

Atkinson, R. and Arey, J.: Atmospheric degradation of volatile organic compounds, Chem. Rev., 103, 4605-4638, https://doi.org/10.1021/cr0206420, 2003.

Atkinson, R. and Aschmann, S. M.: Rate constants for the gasphase reactions of the $\mathrm{NO}_{3}$ radical with a series of organic compounds at 296 \pm 2 K, J. Phys. Chem., 92, 3454-3457, https://doi.org/10.1021/j100323a028, 1988.

Atkinson, R. and Aschmann, S. M. : Rate Constants for the GasPhase Reactions of the $\mathrm{OH}$ Radical with a Series of Aromatic Hydrocarbons at 296 $\pm 2 \mathrm{~K}$, Int. J. Chem. Kinet., 21, 355-365, https://doi.org/10.1002/kin.550210506, 1989.

Atkinson, R., Baulch, D. L., Cox, R. A., Crowley, J. N., Hampson, R. F., Hynes, R. G., Jenkin, M. E., Rossi, M. J., Troe, J., and IUPAC Subcommittee: Evaluated kinetic and photochemical data for atmospheric chemistry: Volume II - gas phase reactions of organic species, Atmos. Chem. Phys., 6, 3625-4055, https://doi.org/10.5194/acp-6-3625-2006, 2006.

Atkinson, R., Plum, C. N., Carter, W. P. L., Winer, A. M., and Pitts Jr., J. N.: Rate constants for the gas-phase reactions of nitrate radicals with a series of organics in air at $298 \pm 1 \mathrm{~K}$, J. Phys. Chem., 88, 1210-1215, https://doi.org/10.1021/j150650a039, 1984.

Ballesteros, B., Garzón, A., Jiménez, E., Notario, A., and Albaladejo, J.: Relative and absolute kinetic studies of 2-butanol and related alcohols with tropospheric $\mathrm{Cl}$ atoms $J$, Phys. Chem. Chem. Phys., 9, 1210-1218, https://doi.org/10.1039/B614531K, 2007.

Bradley, W. R., Wyatt, S. E., Wells, J. R., Henley, M. V., and Graziano, G. M.: The Hydroxyl Radical Reaction Rate Constant and Products of Cyclohexanol, Int. J. Chem. Kinet., 33, 108-117, 2001.

Brauers, T. and Finlayson-Pitts, B. J.: Analysis of relative rate measurements, Int. J. Chem. Kinet., 29, 665-672, https://doi.org/10.1002/(SICI)1097-4601(1997)29:9<665::AIDKIN3>3.0.CO;2-S, 1997.

Calvert, J. G., Mellouki, A., Orlando, J. J., Pilling, M. J., and Wallington, T. J.: The mechanisms of atmospheric oxidation of the oxygenates, Oxford University Press, New York, 2011.

Caravan, R. L., Shannon, R. J., Lewis, T., Blitz, M. A., and Heard, D. E.: Measurements of Rate Coefficients for Reactions of $\mathrm{OH}$ with Ethanol and Propan-2-ol at Very Low Temperatures, J. Phys. Chem. A, 119, 7130-7137, https://doi.org/10.1021/jp505790m, 2015.

Cavalli, F., Geiger, H., Barnes, I., and Becker, K. H.: FTIR Kinetic, Product, and Modeling Study of the OH-Initiated Oxidation of 1-Butanol in Air, Environ. Sci. Technol., 36, 1263-1270, https://doi.org/10.1021/es010220s, 2002.
Ceacero-Vega, A. Ballesteros, B., Albaladejo, J., Bejan, I., and Barnes, I.: Temperature dependence of the gas-phase reactions of $\mathrm{Cl}$ atoms with propene and 1-butene between $285<\mathrm{T}<313 \mathrm{~K}$, Chem. Phys. Lett., 484, 10-13, https://doi.org/10.1016/j.cplett.2009.10.080, 2009.

Ceacero-Vega, A. A., Ballesteros, B., Bejan, I., Barnes, I., Jiménez, E., and Albaladejo, J.: Kinetics and Mechanisms of the Tropospheric Reactions of Menthol, Borneol, Fenchol, Camphor, and Fenchone with Hydroxyl Radicals (OH) and Chlorine Atoms (Cl), J. Phys. Chem. A., 116, 4097-4107, https://doi.org/10.1021/jp212076g, 2012.

Chen, L., Takenaka N., Bandow, H., and Maeda, Y.: Henry's law constants for C2-C3 fluorinated alcohols and their wet deposition in the atmosphere, Atmos. Environ., 37, 4817-4822, https://doi.org/10.1016/j.atmosenv.2003.08.002, 2003.

Cheung, C. S. and Huang, Z.: Effect of n-pentanol addition on the combustion, performance and emission characteristics of a direct-injection diesel engine, Energy 70, 172-80, https://doi.org/10.1016/j.energy.2014.03.106, 2014.

D'Anna, B., Andresen, W., Gefen, Z., and Nielsen, C. J.: Kinetic study of $\mathrm{OH}$ and $\mathrm{NO}_{3}$ radical reactions with 14 aliphatic aldehydes, Phys. Chem. Chem. Phys., 3, 3057-3063, https://doi.org/10.1039/B103623H, 2001.

Dash, M. R. and Rajakumar, B.: Experimental and theoretical rate coefficients for the gas phase reaction of $\beta$ Pinene with $\mathrm{OH}$ radical, Atmos. Environ., 79, 161-171, https://doi.org/10.1016/j.atmosenv.2013.05.039, 2013.

Ezzel, M. J., Wang, W., Ezell, A. A., Soskin, G., and FinlaysonPitts, B. J.: Kinetics of reactions of chlorine atoms with a series of alkenes at $1 \mathrm{~atm}$ and $298 \mathrm{~K}$ : structure and reactivity, Phys. Chem. Chem. Phys., 1, 5813-5820, https://doi.org/10.1039/B207529F, 2002.

Farrugia, L. N., Bejan, I., Smith, S. C., Medeiros, D. J., and Seakins, P. W.: Revised structure activity parameters derived from new rate coefficient determinations for the reactions of chlorine atoms with a series of seven ketones at $290 \mathrm{~K}$ and $1 \mathrm{~atm}$, Chem. Phys. Lett., 640 87-93, https://doi.org/10.1016/j.cplett.2015.09.055, 2015.

Finlayson-Pitts, B. J. and Pitts, J. N.: Chemistry of the Upper and Lower Atmosphere: Theory, Experiments, and Applications, Academic Press, San Diego, 2000.

Gallego-Iniesta, M. P., Moreno, A., Martín, P., Tapia, A., Cabañas, B., and Salgado, M. S.: Reactivity of 2-ethyl-1-hexanol in the atmosphere, Phys. Chem. Chem. Phys., 12, 3294-3300, https://doi.org/10.1039/B923899A, 2010.

Gallego-Iniesta, M. P., Cabañas, B., Salgado, M. S. Martinez, E., and Martin, P.: Estimation of gas-phase rate coefficients for the reactions of a series of $\alpha, \beta$-unsaturated esters with $\mathrm{OH}, \mathrm{NO}_{3}, \mathrm{O}_{3}$ and $\mathrm{Cl}$, Atmos. Environ., 90, 133-145, https://doi.org/10.1016/j.atmosenv.2014.03.036, 2014.

Garzón, A., Cuevas, C. A., Ceacero, A. A., Notario, A., Albaladejo, J., and Fernández-Gómez, M.: Atmospheric reactions $\mathrm{Cl}+\mathrm{CH} 3$ $-\left(\mathrm{CH}_{2}\right)_{n}-\mathrm{OH}(\mathrm{n}=0-4)$ : A kinetic and theoretical study, J. Chem. Phys., 125, 104305-104315, https://doi.org/10.1063/1.2244556, 2006.

Grosjean, D.: Atmospheric chemistry of alcohols, J. Brazil. Chem. Soc., 8, 433-442, https://doi.org/10.1590/S0103$50531997000500002,1997$. 
Herath, N. T., Orozco, I., Clinch, E. C., and Marshall, P.: Relative Rate Studies of the Reactions of Atomic Chlorine with Acetone and Cyclic Ketones, Int. J. Chem. Kinet., 50, 41-46, https://doi.org/10.1002/kin.21138, 2018.

Hurley, M. D., Wallington, T. J., Laursen, L., Javadi, M. S., Nielsen, O. J., Yamanaka, T., and Kawasaki, M.: Atmospheric Chemistry of n-Butanol: Kinetics, Mechanisms, and Products of $\mathrm{Cl}$ Atom and $\mathrm{OH}$ Radical Initiated Oxidation in the Presence and Absence of $\mathrm{NO}_{x}$, J. Phys. Chem. A, 113, 7011-7020, https://doi.org/10.1021/jp810585c, 2009.

Jenkin, M. E., Valorso, R., Aumont, B., Rickard, A. R., and Wallington, T. J.: Estimation of rate coefficients and branching ratios for gas-phase reactions of $\mathrm{OH}$ with aliphatic organic compounds for use in automated mechanism construction, Atmos. Chem. Phys., 18, 9297-9328, https://doi.org/10.5194/acp18-9297-2018, 2018.

Jiménez, E., Lanza, B., Garzón, A., Ballesteros, B., and Albaladejo, J.: Atmospheric Degradation of 2-Butanol, 2-Methyl-2butanol, and 2,3-Dimethyl-2-butanol: OH Kinetics and UV Absorption Cross Sections, J. Phys. Chem. A., 109, 10903-10909, https://doi.org/10.1021/jp054094g, 2005.

Karabektas, M. and Hosoz, M.: Performance and emission characteristics of a diesel engine using isobutanoldiesel fuel blends, Renew Energy, 34, 1554-1559, https://doi.org/10.1016/j.renene.2008.11.003, 2009.

Kerdouci, J., Picquet-Varrault, B., and Doussin, J. F.: Prediction of Rate Constants for Gas-Phase Reactions of Nitrate Radical with Organic Compounds: A New StructureActivity Relationship, Chem. Phys. Chem., 11, 3909-3920, https://doi.org/10.1002/cphc.201000673, 2010.

Kerdouci, J., Picquet-Varrault, B., and Doussin, J. F.: Structure-activity relationship for the gas-phase reactions of $\mathrm{NO}_{3}$ radical with organic compounds: Update and extension to aldehydes, Atmos. Environ. 84, 363-372, https://doi.org/10.1016/j.atmosenv.2013.11.024, 2014.

Kumar, B. R. and Saravanan, S.: Use of higher alcohol biofuels in diesel engines: A review, Renew. Sust. Energ. Rev., 60, 84-115, https://doi.org/10.1016/j.rser.2016.01.085, 2016.

Kwok, E. S. C. and Atkinson, R.: Estimation of Hydroxyl Radical Reaction Rate Constants For Gas-Phase Organic Compounds Using A Structure-Reactivity Relationship: An Update, Atmos. Environ., 29, 1685-1695, https://doi.org/10.1016/13522310(95)00069-B, 1995.

Lapuerta, M., García-Contreras, R., Campos-Fernández, J., and Dorado, P.: Stability, lubricity, viscosity, and cold-flow properties of alcohol-diesel blends, Energy Fuels, 24, 4497-4502, https://doi.org/10.1021/ef100498u, 2010.

Li, F., Yi, B., Song, L., Fu, W., Liu, T., Hu, H., and Lin, Q.: Macroscopic spray characteristics of long-chain alcohol-biodiesel fuels in a constant volume chamber, P. I. Mech. Eng. A-J. POW., 232, 195-207, https://doi.org/10.1177/0957650917721336, 2017.

Lopes, M., Serrano, L., Ribeiro, I., Cascao, P., and Pires, N.: Emissions characterization from EURO 5 diesel/biodiesel passenger car operating under the new European driving cycle, Atmos. Environ., 84, 339-348, https://doi.org/10.1016/j.atmosenv.2013.11.071, 2014.

Martin, P., Cabañas, B., Colmenar, I., Salgado, M. S., Villanueva, F., and Tapia, A.: Reactivity of E-butenedial with the major atmospheric oxidants, Atmos. Environ., 70, 351-360, https://doi.org/10.1016/j.atmosenv.2013.01.041, 2013.

McGillen, M. R., Baasandorj, M., and Burkholder, J. B.: Gas-Phase Rate Coefficients for the $\mathrm{OH}+\mathrm{n}-$, i-, s-, and t-Butanol Reactions Measured Between 220 and $380 \mathrm{~K}$ : Non-Arrhenius Behavior and Site- Specific Reactivity, J. Phys. Chem. A, 117, 46364656, https://doi.org/10.1021/jp402702u, 2013.

McGillen, M. R., Tyndall, G. S., Orlando, J. J., Pimentel, A. S., Medeiros, D. J., and Burkholder, J. B.: Experimentally Determined Site-Specific Reactivity of the Gas-Phase $\mathrm{OH}$ and $\mathrm{Cl}+$ i-Butanol Reactions Between 251 and 340 K, J. Phys. Chem. A, 120, 9968-9981, https://doi.org/10.1021/acs.jpca.6b09266, 2016.

Mellouki, A., Wallington, T. J., and Chen, J.: Atmospheric chemistry of oxygenated volatile organic compounds: impacts on air quality and climate, Chem. Rev., 115, 3984-4014, https://doi.org/10.1021/cr500549n, 2015.

Moc, J. and Simmie, J. M.: Hydrogen Abstraction from n-Butanol by the Hydroxyl Radical: High Level Ab Initio Study of the Relative Significance of Various Abstraction Channels and the Role of Weakly Bound Intermediates, J. Phys. Chem. A, 114, 55585564, https://doi.org/10.1021/jp1009065, 2010.

Moreno, A., Salgado, S., Martin, P., Martinez, E., and Cabañas, B.: Kinetic Study of the Gas Phase Reactions of a Series of Alcohols with the $\mathrm{NO}_{3}$ Radical, J. Phys. Chem. A, 116, 42, 10383-10389, https://doi.org/10.1021/jp305682h, 2012.

Moreno, A., Salgado, S., Taccone, R., Martín, P., and Cabañas, B.: Atmospheric degradation of saturated alcohols: room temperature rate coefficients for $\mathrm{NO}_{3}$ radical reactions, Atmos. Environ., 96, 229-235, https://doi.org/10.1016/j.atmosenv.2014.07.037, 2014.

Murty, M. R. V. S, Prasada, R. N., Prabhakar, S., and Vairamani, M.: Chemical ionization mass spectral analysis of pinacolyl alcohol and development of derivatization method using p-tolyl isocyanate, Anal. Methods-UK, 2, 1599-1605, https://doi.org/10.1039/C0AY00346H, 2010.

Nelson, L., Rattigan, O., Neavyn, R., Sidebottom, H., Treacy, J., and Nielsen, O. J.: Absolute and Relative Rate Constants for the Reactions of Hydroxyl Radicals and Chlorine Atoms with a Series of Aliphatic Alcohols and Ethers at 298 K, Int. J. Chem. Kinet., 22, 1111-1126, https://doi.org/10.1002/kin.550221102, 1990.

Nguyen, H. T., Takenaka, N., Bandow, H., Maeda, Y., Oliva, S. T., Botelho, M. M., and Tavares T. M.: Atmospheric alcohols and aldehydes concentrations measured in Osaka, Japan and in Sao Paulo, Brazil, Atmos. Environ., 35, 3075-3083, https://doi.org/10.1016/S1352-2310(01)00136-4, 2001.

Ozsezen, N. A., Turkcan, A., Sayin, C., and Canakci, M.: Comparison of performance and combustion parameters in a heavyduty diesel engine fueled with iso-butanol/diesel fuel blends, Energ. Explor. Exploit., 29, 525-541, https://doi.org/10.1260/01445987.29.5.525, 2011.

Poutsma, M. L.: Evolution of Structure-Reactivity Correlations for the Hydrogen Abstraction Reaction by Chlorine Atom, J. Phys. Chem. A, 117, 687-703, https://doi.org/10.1021/jp310970t, 2013.

Platt, U. and Janssen, C.: Observation and role of the free radicals $\mathrm{NO}_{3}, \mathrm{ClO}, \mathrm{BrO}$ and IO in the troposphere, Faraday Discuss., 100, 175-198, https://doi.org/10.1039/FD9950000175, 1995. 
Prinn, R. G., Huang, J., Weiss, R. F., Cunnold, D. M., Fraser, P. J., Simmonds, P. G., McCulloch, A., Harth, C., Salameh, P., O'Doherty, S., Wang, R. H. J., Porter, L., and Miller, R. B.: Evidence for Substantial Variations of Atmospheric Hydroxyl Radicals in the Past Two Decades, Science, 292, 1882-1888, https://doi.org/10.1126/science.1058673, 2001.

Ren, Y., Huang, Z., Miao, H., Di, Y., Jiang, D., Zeng, K., Liu, B., and Wang, X.: Combustion and emissions of a DI diesel engine fuelled with diesel-oxygenate blends, Fuel, 87, 2691-2697, https://doi.org/10.1016/j.fuel.2008.02.017, 2008.

Ren, Y., Wang, J., Grosselin, B., Daele, V., and Mellouki, A.: Kinetic and product studies of $\mathrm{Cl}$ atoms reactions with a series of branched ketones, J. Environ. Sci., 71, 271-282, https://doi.org/10.1016/j.jes.2018.03.036, 2018.

Sander, R.: Compilation of Henry's law constants (version 4.0) for water as solvent, Atmos. Chem. Phys., 15, 4399-4981, https://doi.org/10.5194/acp-15-4399-2015, 2015.

Sarathy, M., Oßwald P., Hansen, N., and Kohse-Höinghaus, K.: Alcohol combustion chemistry, Prog. Energ. Combust., 44, 40-102, https://doi.org/10.1016/j.pecs.2014.04.003, 2014.

Schott, G. and Davidson, N.: Shock Waves in Chemical Kinetics: The Decomposition of $\mathrm{N}_{2} \mathrm{O}_{5}$ at High Temperatures, J. Am. Chem. Soc., 80, 1841-1853, https://doi.org/10.1021/ja01541a019, 1958.

Sikarwara, V. S., Zhao, M., Fennell, P. S., Shah, N., and Anthony, E. J.: Progress in biofuel production from gasification, Prog. Energ. Combust., 61, 189-248, https://doi.org/10.1016/j.pecs.2017.04.001, 2017.

Smith, I. W. M. and Ravishankara, A. R. J.: Role of Hydrogen-Bonded Intermediates in the Bimolecular Reactions of the Hydroxyl Radical, Phys. Chem. A, 106, 4798-4807, https://doi.org/10.1021/jp014234w, 2002.

Spicer, C., Chapman, E. G., Finalysson-Pitts, B. J., Plastridege, R. A., Hybbe, J. M., Fast, J. D., and Berkowitz, C. M.: Unexpectedly high concentrations of molecular chlorine in coastal air, Nature, 394, 353-356, https://doi.org/10.1038/28584, 1998.

Tapia, A., Villanueva, F., Salgado, M. S., Cabañas, B., Martínez, E., and Martín, P.: Atmospheric degradation of 3-methylfuran: kinetic and products study, Atmos. Chem. Phys., 11, 3227-3241, https://doi.org/10.5194/acp-11-3227-2011, 2011.

Taylor, W. D., Alston, T. D., Moscato, M. J., Fazekas, G. B., Kozlowski, R., and Takacs, G. A.: Atmospheric photodissociation lifetimes for nitromethane, methyl nitrite, and methyl nitrate, Int. J. Chem. Kinet., 12, 231-240, https://doi.org/10.1002/kin.550120404, 1980.
Thevenet, R., Mellouki, A., and Bras, G. L.: Kinetics of $\mathrm{OH}$ and $\mathrm{Cl}$ Reactions with a Series of Aldehydes, Int. J. Chem. Kinet., 32, 676-685, https://doi.org/10.1002/10974601(2000)32:11<676::AID-KIN3>3.0.CO;2-V, 2000.

Tuazon, E. C. and Atkinson, R. A.: Product Study of the Gas-Phase Reaction of Isoprene with the $\mathrm{OH}$ Radical in the Presence of $\mathrm{NO}_{\mathrm{x}}$, Int. J. Chem. Kinet., 22, 1221-1236, https://doi.org/10.1002/kin.550221202, 1990.

Tuazon, E. C., Leod, H. M, Atkinson, R., and Carter, W. P. L.: $\alpha-$ Dicarbonyl Yields from the $\mathrm{NO}_{x}$ Air Photooxidations of a Series of Aromatic Hydrocarbons in Air, Environ. Sci. Technol., 20, 383-387, https://doi.org/10.1021/es00146a010, 1986.

Vereecken, L., Aumont, B., Barnes, I., Bozzelli, J. W., Goldman, M. J., Green, W. H., Madronich, S., Mcgillen, M. R., Mellouki, A., Orlando, J. J., Picquet-Varrault, B., Rickard, R., Stockwell, W. R., Wallington, T. J., and Carter, W. P. L.: Perspective on Mechanism Development and Structure-Activity Relationships for GasPhase Atmospheric Chemistry, Int. J. Chem. Kinet., 50, 435-469, https://doi.org/10.1002/kin.21172, 2018.

Wallington, T. J. and Kurylo, M. J.: Flash Photolysis Resonance Fluorescence Investigation of the Gas-Phase Reactions of $\mathrm{OH}$ Radicals with a Series of Aliphatic Ketones over the Temperature Range 240-440 K, J. Phys. Chem., 91, 5050-5054, https://doi.org/10.1021/j100303a033, 1987.

Wallington, T. J., Skwes, L. M., Siegl, W. O., Wu, C., and Japar, S. M.: Gas phase reaction of $\mathrm{Cl}$ atoms with a series of oxygenated organic species at $295 \mathrm{~K}$, Int. J. Chem. Kinet., 20, 867-875, https://doi.org/10.1002/kin.550201105, 1988.

Wayne, R. P.: Chemistry of Atmospheres, Oxford University Press, New York, 2000.

Wayne, R. P., Barnes, I., Biggs, P., Burrows, J. P., Canosa-Mas, C. E., Hjorth, J., LeBras, G., Moortgat, G. K., Perner, D., Poulet, G., Restelli, G., and Sidebottom, H.: The nitrate radical: Physics, chemistry, and the atmosphere, Atmos. Environ., 25A, 1-203, https://doi.org/10.1016/0960-1686(91)90192-A, 1991.

Welz,O., Klippenstein, S., O., J., Harding, L. B., Taatjes, C. A., and Zádor, J.: Unconventional Peroxy Chemistry in Alcohol Oxidation: The Water Elimination Pathway, J. Phys. Chem. Lett., 43, 350-354, https://doi.org/10.1021/jz302004w, 2013.

Ziemann P. and Atkinson R.: Kinetics, products, and mechanisms of secondary organic aerosol formation, Chem. Soc. Rev., 41, 65826605, https://doi.org/10.1039/C2CS35122F, 2012. 